\title{
Quantitative interpretation of atmospheric carbon records over the last glacial termination
}

\author{
Peter Köhler ${ }^{1, *}$, Hubertus Fischer ${ }^{1}$, Guy Munhoven ${ }^{2}$, and Richard E. Zeebe ${ }^{1,3}$ \\ ${ }^{1}$ Alfred Wegener Institute for Polar and Marine Research, P.O. Box 1201 61, D-27515 \\ Bremerhaven, Germany. \\ *Corresponding author: Phone: +49 4714831 1687, Fax: +49 47148311149 , \\ pkoehler@awi-bremerhaven.de \\ ${ }^{2}$ Laboratoire de Physique Atmosphérique et Planétaire, Institut d'Astrophysique et de \\ Géophysique, Université de Liège, 5 avenue de Cointe, B-4000 Liège, Belgium \\ ${ }^{3}$ Now at the Department of Oceanography, University of Hawai' $i$ at Manoa, 1000 Pope Road, \\ Marine Sciences Building, Honolulu, HI 96822, USA
}

Published in

Global Biogeochemical Cycles

doi: 10.1029/2004GB002345

Initial submission on July 19, 2004

Resubmission of final version at July 13, 2005

Accepted at August 25, 2005

An edited version of this paper was published by AGU on December 13, 2005.

Copyright 2005 American Geophysical Union.

Citation: Köhler, P., H. Fischer, G. Munhoven, and R. E. Zeebe (2005), Quantitative interpretation of atmospheric carbon records over the last glacial termination, Global

Biogeochem. Cycles, 19, GB4020, doi:10.1029/2004GB002345. 


\title{
Quantitative interpretation of atmospheric carbon records over the last glacial termination
}

\author{
Peter Köhler $^{1, *}$, Hubertus Fischer ${ }^{1}$, Guy Munhoven ${ }^{2}$, and Richard E. Zeebe ${ }^{1,3}$ \\ ${ }^{1}$ Alfred Wegener Institute for Polar and Marine Research, P.O. Box 1201 61, D-27515 Bremerhaven, Germany. \\ *Corresponding author: Phone: +49 4714831 1687, Fax: +49 4714831 1149, pkoehler@awi-bremerhaven.de \\ ${ }^{2}$ Laboratoire de Physique Atmosphérique et Planétaire, Institut d'Astrophysique et de Géophysique, Université de Liège, 5 \\ avenue de Cointe, B-4000 Liège, Belgium \\ ${ }^{3}$ Now at the Department of Oceanography, University of Hawai'i at Manoa, 1000 Pope Road, Marine Sciences Building, \\ Honolulu, HI 96822, USA
}

\begin{abstract}
.
The glacial/interglacial rise in atmospheric $p \mathrm{CO}_{2}$ is one of the best known changes in paleoclimate research - yet the cause for it is still unknown. Forcing the coupled oceanatmosphere-biosphere box model of the global carbon cycle BICYCLE with proxy data over the last glacial termination we are able to quantitatively reproduce transient variations in $p \mathrm{CO}_{2}$ and its isotopic signatures $\left(\delta^{13} \mathrm{C}, \Delta^{14} \mathrm{C}\right)$ observed in natural climate archives. The sensitivity of BICYCLE to high or low latitudinal changes is comparable to other multibox models or more complex ocean carbon cycle models, respectively. The processes considered here ranked after their contribution to the glacial/interglacial rise in $p \mathrm{CO}_{2}$ in decreasing order are: the rise in Southern Ocean vertical mixing rates $(>30 \mathrm{ppmv})$, decreases in alkalinity and carbon inventories $(>30 \mathrm{ppmv})$, the reduction of the biological pump ( $\sim 20$ ppmv), the rise in ocean temperatures $(15-20 \mathrm{ppmv})$, the resumption of ocean circulation $(15-20 \mathrm{ppmv})$, and coral reef growth $(<5 \mathrm{ppmv})$. The regrowth of the terrestrial biosphere, sea level rise and the increase in gas exchange through reduced sea ice cover operate in the opposite direction, decreasing $p \mathrm{CO}_{2}$ during Termination I by $\sim 30 \mathrm{ppmv}$. According to our model the sequence of events during Termination I might have been the following: A reduction of aeolian iron fertilization in the Southern Ocean together with a breakdown in Southern Ocean stratification, the latter caused by rapid sea ice retreat, trigger the onset of the $p \mathrm{CO}_{2}$ increase. After these events the reduced North Atlantic Deep Water (NADW) formation during the Heinrich 1 event and the subsequent resumption of ocean circulation at the beginning of the Bølling-Allerød warm interval are the main processes determining the atmospheric carbon records in the subsequent time period of Termination I. We further deduce that a complete shutdown of the NADW formation during the Younger Dryas was very unlikely. Changes in ocean temperature and the terrestrial carbon storage are the dominant processes explaining atmospheric $\delta^{13} \mathrm{C}$ after the $\mathrm{B} ø$ lling-Allerød warm interval.
\end{abstract}

Index terms: 0322 Constituent sources and sinks, 4805 Biogeochemical cycles (1615), 4806 Carbon cycling
Key words: carbon cycle, box model, glacial/interglacial, $\mathrm{CO}_{2}$, Termination I.

\section{Introduction}

One crucial question of paleoclimate research still unraveled is the conceptual and quantitative understanding of glacial/interglacial $(\mathrm{G} / \mathrm{IG})$ changes in atmospheric $p \mathrm{CO}_{2}$. During the transition from the Last Glacial Maximum (LGM) 23-19 kyr before present (BP) to the beginning of the Holocene around $11 \mathrm{kyr}$ BP measurements in ice cores reveal an increase of about 80 parts per million by volume (ppmv) [Barnola et al., 1987; Fischer et al., 1999; Monnin et al., 2001]. Theories proposed in the past [see reviews in Archer et al., 2000a; Sigman and Boyle, 2000] have focused on the intensities or specific aspects of either the physical or the biological pump which transport carbon from the surface to the deep ocean.

Variations in the physical pump by large changes in vertical ocean mixing [Toggweiler, 1999], the strength of the thermohaline circulation (THC) [Heinze et al., 1991], or sea ice cover limiting gas exchange rates [Stephens and Keeling, 2000] result in $p \mathrm{CO}_{2}$ variations in the atmosphere. Iron fertilization in high nitrate low chlorophyll (HNLC) areas was put forward as a process acting on the biological pump which reduces $p \mathrm{CO}_{2}$ in the LGM via increased marine export production [Martin, 1990; Watson et al., 2000; Ridgwell and Watson, 2002; Bopp et al., 2003; Ridgwell, 2003b]. The rain ratio of organic matter to calcium carbonate $\left(\mathrm{CaCO}_{3}\right)$ connects the two main export processes of the biological pump. Changes in the rain ratio on G/IG timescales were proposed as hypothesis to explain observed variations in atmospheric $p \mathrm{CO}_{2}$ [Archer and Maier-Reimer, 1994]. While there is nowadays evidence that the rain ratio has remained fairly constant [Sigman et al., 1998; Klaas and Archer, 2002; Ridgwell, 2003a], rain ratio changes in relation to Southern Ocean processes as a potentially viable explanation for lower glacial $p \mathrm{CO}_{2}$ have recently been discussed [e.g. Matsumoto et al., 2002]. Additionally, inventories of dissolved inorganic carbon (DIC) and alkalinity (ALK) in the ocean 
are perturbed by fluxes of carbonate $\left(\mathrm{CO}_{3}^{2-}\right)$ and bicarbonate $\left(\mathrm{HCO}_{3}^{-}\right)$in and out of the ocean via continental weathering [Munhoven, 2002; Amiotte-Suchet et al., 2003], shallow water carbonate production through coral reef growth [Berger, 1982; Opdyke and Walker, 1992; Vecsei and Berger, 2004] and dissolution and sedimentation in the deep ocean [e.g. Berger, 1968; Berger and Keir, 1984; Broecker and Takahashi, 1978; Crowley, 1983; Peterson and Prell, 1985; Curry and Lohmann, 1986; Broecker and Peng, 1987; Farrell and Prell, 1989; Archer, 1991; Milliman, 1993; Howard and Prell, 1994; Zeebe and Westbroek, 2003]. The first conceptual ocean carbon cycle box models proposed either variations in the ocean circulation and high latitude mixing rates or enhanced glacial high latitude nutrient utilization invoking greater marine biological productivity as main drivers for the G/IG rise in $p \mathrm{CO}_{2}$ [Knox and B.McElroy, 1984; Sarmiento and Toggweiler, 1984; Siegenthaler and Wenk, 1984] . In various studies, the Southern Ocean was identified as a key area where major variations in the global carbon cycle and climate system were initiated leading to the G/IG transitions [Toggweiler and Sarmiento, 1985; Sigman and Boyle, 2000; Stephens and Keeling, 2000; Knorr and Lohmann, 2003].

In this study we use for the first time a transient modeling approach to disentangle these effects which act at different times during the transition and to propose for the first time a consistent picture to explain both changes in atmospheric $p \mathrm{CO}_{2}$ and its stable isotopic signature $\delta^{13} \mathrm{C}$ over time. Our results are also in line with the atmospheric $\Delta^{14} \mathrm{C}$ record and observations of $\delta^{13} \mathrm{C}$ in deep sea sediments. To this end we force our simple ocean-atmosphere-biosphere box model forward in time, using the temporal information on boundary conditions of the global carbon cycle as revealed by proxy records in ice and sediment cores. We intentionally use a simple model which is sufficiently constrained by those boundary conditions. We concentrate on the last transition for which all data relevant for our study are available.

\section{Model description}

We use our Box model of the Isotopic Carbon cYCLE (named BICYCLE, Fig. 1) consisting of a modified version of a globally averaged box model of the terrestrial biosphere [Emanuel et al., 1984] recently applied on glacial timescales [for details see Köhler and Fischer, 2004] coupled to an updated version of a multi-box model of the ocean/atmosphere subsystem [Munhoven and François, 1996; Munhoven, 1997]. While the atmosphere consists of one well mixed box only, the global oceans are resolved by ten homogeneous reservoirs (five surface, two intermediate, three deep, Fig. 2). The ocean model is comparable to well tested models such as PANDORA (10 ocean boxes) [Broecker and Peng, 1986] or CYCLOPS (14 ocean boxes) [Keir, 1988]. The terrestrial biosphere is considered globally averaged by seven compartments representing $\mathrm{C}_{3}$ and $\mathrm{C}_{4}$ ground vegetation, trees, and soil carbon with different turnover times. Alternatively, any assumed change in the terrestrial carbon stocks or the output of more sophisticated dy- namic global vegetation models (DGVM) can be applied as additional boundary conditions.

The geometry of the oceanic reservoirs is based upon realistic bathymetric profiles and changes as a function of the prescribed sea level evolution. The model includes mass balance equations for the carbon stocks of the biospheric compartments, for DIC, total alkalinity, phosphate (chosen as the limiting macro nutrient) and oxygen in the ten oceanic reservoirs, for $\mathrm{CO}_{2}$ in the atmospheric reservoir, and the ${ }^{13} \mathrm{C}$ and ${ }^{14} \mathrm{C}$ isotopic signatures in all of them. The mass balance equations include terms to represent the air-sea exchange of $\mathrm{CO}_{2}$ and the transport of dissolved species by water circulation. Further taken into account is the production of organic and inorganic (carbonate) particles by marine biological activity in the surface layer. Organic particles and inorganic carbonate rain down to the intermediate and deep reservoirs where they are remineralised or deposited.

\section{Preindustrial parameter setting}

The original ocean — atmosphere model [Munhoven, 1997] is updated in various ways:

We used C:N:P:O $\mathrm{O}_{2}=123: 17: 1:-165$ as elemental (Redfield) ratios during marine production and remineralization [Körtzinger et al., 2001]. The chemical equilibrium of the oceanic carbonate system is based on a recent review [Zeebe and Wolf-Gladrow, 2001] with updates of the dissociation constants $\mathrm{pK}_{1}$ and $\mathrm{pK}_{2}$ [Prieto and Millero, 2002]. Recent ocean temperature and salinity are prescribed from data based on the World Ocean Atlas [Levitus and Boyer, 1994b; Levitus et al., 1994].

Mean annual sea ice covers of the Arctic and Southern Ocean surface boxes $\left(10 \times 10^{12} \mathrm{~m}^{2}\right.$ each $)$ are realized by reducing gas exchange rates relative to areal ice cover based on current knowledge on recent sea ice extents [Cavalieri et al., 1997; Vinnikov et al., 1999; Fichefet et al., 2003].

The ocean-atmosphere gas exchange is a function of temperature via the solubility of $\mathrm{CO}_{2}$ and piston velocity (2.5 and $7.5 \times 10^{-5} \mathrm{~m} \mathrm{~s}^{-1}$ for low and high latitudes, respectively) which is based on wind speed to resolve latitudinal differences [Heimann and Monfray, 1989; Sarmiento et al., 1992; Wanninkhof, 1992]. The average gas exchange coefficient $\left(0.051 \mathrm{~mol} \mathrm{~m}^{-2} \mathrm{yr}^{-1} \mu \mathrm{atm}^{-1}\right)$ is of the same order as in ${ }^{13} \mathrm{C} /{ }^{12} \mathrm{C}$ studies [Heimann and Maier-Reimer, 1996] and leads to a preindustrial gross flux of $\mathrm{CO}_{2}$ between ocean surface and atmosphere of about $60 \mathrm{PgC} \mathrm{yr}^{-1}$.

The isotopic fractionation during the gas exchange is a function of temperature [Zhang et al., 1995]. The fractionation during marine organic production follows a temperature and $\mathrm{CO}_{2}$ (aq) dependent scheme [Rau et al., 1996, 1997; Ridgwell, 2001], while for inorganic $\mathrm{CaCO}_{3}$ production a simple temperature-dependent fractionation is assumed [Mook, 1986].

Ocean circulation and especially recent deep water production (DWP) is based on WOCE data [Ganachaud and Wunsch, 2000]. We use $16 \mathrm{~Sv}\left(1 \mathrm{~Sv}=10^{6} \mathrm{~m}^{3} \mathrm{~s}^{-1}\right)$ of North Atlantic Deep Water (NADW) formation and $9 \mathrm{~Sv}$ for the effective production of Antarctic Bottom Water (AABW) (Fig. 
2). The latter results from the difference between $21 \pm 6$ Sv down- and $8 \pm 9 \mathrm{~Sv}$ upwelling in the Southern Ocean as estimated by Ganachaud and Wunsch [2000]. The missing DWP of AABW is matched by the vertical mixing fluxes. Data suggest equatorial mixing between surface and intermediate boxes [20 Sv Atlantic, 60 Sv Indo-Pacific, McPhaden and Zang, 2002] which is driven by equatorial upwelling, Ekman pumping [Wunsch, 1984] and subduction [Qiu and Huang, 1995]. The vertical exchange in high latitudes (60 Sv) mainly occurs in the Indo-Pacific section of the Southern Ocean [Sloyan and Rintoul, 2001]. To obtain best agreements between the steady state global behavior of the oceanic module for preindustrial conditions with observations (DIC, alkalinity [Takahashi et al., 1981; Millero et al., 1998; Key et al., 2004, and GLobal Ocean Data Analysis Project GLODAP at http://ferret.pmel.noaa.gov/GLODAP], $\mathrm{PO}_{4}$ [Conkright et al., 1994], $\mathrm{O}_{2}$ [Levitus and Boyer, 1994a], $\delta^{13} \mathrm{C}$ [Kroopnick, 1985], $\Delta^{14} \mathrm{C}$ [Stuiver et al., 1981]) we had to revise original vertical mixing strengths and divided them by a factor of two. This discrepancy is attributed to our coarse ocean model resolution especially in the vertical direction and brings our ocean circulation pattern closer to other box model studies [e.g. Broecker and Peng, 1986; Keir, 1988]. Southern Ocean vertical mixing assumed here (20 $\mathrm{Sv}$ ) is thus also of the order of magnitude estimated recently (14 Sv) by a study which applied "residual mean theory" to transient tracer uptake [Ito et al., 2004]. Thus, especially box turnover times and $\Delta^{14} \mathrm{C}$ (Table 1) are now in line with observations [Stuiver et al., 1981], which find a $\Delta^{14} \mathrm{C}$ of $50 \%$ to $-100 \%$ in surface waters and $-80 \%$ to $-200 \%$ in the deep ocean. In our pre-industrial reference scenario, deep Indo-Pacific waters are mostly of NADW origin. The age of these deep Indo-Pacific waters calculated with the box turnover times and consideration of the water transport as depicted in Fig. 2 is estimated to more than 900 years. The recent ${ }^{14} \mathrm{C}$ production rate is set to $450 \mathrm{~mol} \mathrm{yr}^{-1}$ to match radiocarbon decay rates and to allow our simulations to start from steady state, and is, thus, lower than the widely used estimate of Masarik and Beer [1999].

The preindustrial flux of export production of organic matter from the surface to the deep ocean is prescribed at $100 \mathrm{~m}$ water depth with $10{\mathrm{PgC} \mathrm{yr}^{-1}}_{\text {[Schlitzer, 2000; Gnanade- }}$ sikan et al., 2002; Sarmiento et al., 2002]. (Note that Southern Ocean export was not prescribed during transient model runs, cf. Section 5.3). We assume a constant rain ratio between organic and $\mathrm{CaCO}_{3}$ production of 10 [Sigman and Boyle, 2000; Harvey, 2001; Koeve, 2002; Sarmiento et al., 2002; Schiebel, 2002]. Data and modelling constraints on the spatial distribution of the export production find about two thirds of the global export flux in equatorial regions (and there in the coastal upwelling zones), a fourth in the Southern Ocean, 10-20\% in the North Atlantic and very little in the Northern Pacific [Schlitzer, 2000, 2002; Gnanadesikan et al., 2002]. To account for these regional differences in marine production all macro nutrients in the equa-

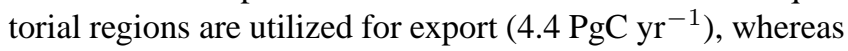
the missing amount of carbon export to reach the proposed global production of $10{\mathrm{PgC} \mathrm{yr}^{-1}}^{-1}$ s supplied by prescribed fluxes in the three high latitudinal areas (North Atlantic:
1.6 $\mathrm{PgC} \mathrm{yr}^{-1}$ ), Southern Ocean: $3.4 \mathrm{PgC} \mathrm{yr}^{-1}$, North Pacific: $0.6 \mathrm{PgC}^{-1}$ ). Since the large nutrient gradients in the equatorial regions are not resolved in our study the export production in our model compared with other studies is higher in the Southern Ocean and lower in the equatorial boxes, but consistent with a previous box model study [Sigman et al., 1998]. From the marine biological production in the surface layers $18 \%$ of the organic material and $80 \% \mathrm{CaCO}_{3}$ reach the deep ocean below $1000 \mathrm{~m}$ depth. If the $\mathrm{O}_{2}$ concentration drops below $4 \mu \mathrm{mol} \mathrm{kg}{ }^{-1}$ the remineralization of organic matter in the deep ocean is assumed to follow the denitrification pathway and thus does not consume any molecular oxygen. This is in line with the Ocean Carbon-Cycle Model Intercomparison Project (OCMIP) 2 protocol and field data on zooplankton abundance [Saltzman and Wishner, 1997]. While anoxic conditions do not occur for preindustrial model conditions, they do occur during time-dependent model scenarios when large changes in oceanic overturning are assumed (to be investigated later on).

In our steady state result of the reference run for the preindustrial climate (Table 1) atmospheric $p \mathrm{CO}_{2}$ settles at 267 ppmv. The $\Delta^{14} \mathrm{C}$ of the ocean boxes as a proxy for model turnover times fall within the ranges observed by Stuiver et al. [1981] with the exception of the deep Southern Ocean where $\Delta^{14} \mathrm{C}$ is about $20 \%$ too heavy.

\section{Model evaluation and sensitivities}

There is an ongoing discussion about the sensitivities of ocean carbon cycle models of various complexity to changes in either the low or the high latitudinal surface ocean [Broecker et al., 1999; Archer et al., 2000b; Toggweiler et al., 2003a,b; Zeebe, 2005]. Thus, it was shown that atmospheric $p \mathrm{CO}_{2}$ calculated with simple box models have a high sensitivity to variations in the high latitudes, while $p \mathrm{CO}_{2}$ derived from multi-box models and particularly GCMs is more sensitive to changes in the low-latitude oceans.

We perform two tests regarding the sensitivity of BICYCLE in the context of other carbon cycle models. First, the model-calculated $p \mathrm{CO}_{2}$ derived by an 'abiotic' ocean is determined to evaluate its high latitudinal sensitivity. This abiotic test is performed by setting marine export fluxes of both organic and inorganic material to zero. The lower the final atmospheric $p \mathrm{CO}_{2}$ of the model, the larger is its highlatitude sensitivity, because of higher solubility of $p \mathrm{CO}_{2}$ in colder surface water. The test was first applied by Archer et al. [2000b] to a variety of different models and extended recently [Zeebe, 2005]. We use the same initialization of the carbonate system to allow comparison with these studies $\left(\mathrm{ALK}=2371 \mu \mathrm{mol} \mathrm{kg}{ }^{-1}\right.$, DIC $=2085 \mu \mathrm{mol} \mathrm{kg}^{-1}$, atmospheric $\left.p \mathrm{CO}_{2}=278 \mathrm{ppmv}\right)$. In this setting BICYCLE has an abiotic $p \mathrm{CO}_{2}$ of $221 \mathrm{ppmv}$, which is in the range of CYCLOPS $\left(p \mathrm{CO}_{2}=221 \mathrm{ppmv}\right)$ and PANDORA $\left(p \mathrm{CO}_{2}=\right.$ 230 ppmv), but lower than most more complex ocean carbon cycle models.

In a second test, the low-latitude sensitivity of the ocean/atmosphere component is tested by calculating the Harvardton Bear Equilibration Index (HBEI) [Broecker 
et al., 1999]. The HBEI is calculated by a perturbation of the solubility of $\mathrm{CO}_{2}$ in the warm equatorial surface ocean. It varies between 0 and 1 and is a measure for the modeled sensitivity of atmospheric $p \mathrm{CO}_{2}$ to changes in the warm low latitudinal surface ocean. HBEI can either be calculated for the perturbations of atmospheric $p \mathrm{CO}_{2}$ or using the warm surface ocean's partial pressure. Typical values are 0.1 for three box ocean models to $0.3-0.4$ for 3D GCMs. As already mentioned [Broecker et al., 1999] the HBEI varies with the strength of the perturbation, but converges with decreasing solubility to stable values. Here, the HBEI of the average warm surface ocean is 0.39 for a decrease in $\mathrm{CO}_{2}$ solubility by $30 \%$, and converges to 0.30 for smaller vales. Thus, BICYCLE is more sensitive to changes in the warm oceans than CYCLOPS $(\mathrm{HBEI}=0.19)$ or PANDORA $(\mathrm{HBEI}=0.22)$ and is close to the warm water sensitivity of 3D GCMs $(0.24-0.32)$. One has to note, that the definition of warm equatorial waters here is slightly different from that of Broecker et al. [1999] who used $40^{\circ} \mathrm{S}-40^{\circ} \mathrm{N}$, while our Atlantic equatorial box reaches as far north as $50^{\circ} \mathrm{N}$.

Taken together, the model sensitivity of the ocean module in BICYCLE - at least of its physical system - is in the range of other multi-box models.

To elucidate the model sensitivity to important parameters we perform some two-dimensional parameter variations (Fig. 3). The atmospheric $p \mathrm{CO}_{2}$ is remarkable stable in response to small changes in ocean circulation (Fig. 3A). A change in NADW formation or Southern Ocean vertical mixing by $25 \%$ would, for example, alter $p \mathrm{CO}_{2}$ by 5 ppmv only. The model is more sensitive to variations in the biological pump (Fig. 3B). Increasing or decreasing marine export production by $25 \%$ alters atmospheric $p \mathrm{CO}_{2}$ by more than 20 ppmv. On the other hand, the model is a factor four less sensitive to changes in the rain ratio. Varying the rain ratio by $25 \%$ changes $p \mathrm{CO}_{2}$ by $\sim 5$ ppmv.

If we compare our ocean setting for the preindustrial reference run (Table 1) with the newest data compilation from GLODAP [Key et al., 2004] and other sources [Kroopnick, 1985; Conkright et al., 1994; Takahashi et al., 2002] we find agreements with our ocean variables (DIC, $\mathrm{ALK}, \mathrm{PO}_{4}$, $\delta^{13} \mathrm{C}, \Delta^{14} \mathrm{C}$ ). DIC, ALK, and $p \mathrm{CO}_{2}$ comparisons are depicted as examples in Fig. 4. Especially, modeled DIC agrees well with the DIC corrected for anthropogenic carbon of GLODAP (Fig. 4B). Modeled ALK in surface waters of the Indo-Pacific and the Southern Ocean (equatorial Atlantic) are about $50 \mu \mathrm{mol} \mathrm{kg}{ }^{-1}$ higher (lower) than in GLODAP (Fig. 4C). The comparison of $p \mathrm{CO}_{2}$ with the climatology of Takahashi et al. [2002], which was here uniformly corrected by 82 ppmv for anthropogenic carbon to yield a similar global mean $p \mathrm{CO}_{2}$, shows clearly that the Atlantic distribution of $p \mathrm{CO}_{2}$ including the North Atlantic sink is reconstructed properly by the model, while regional details of the other surface areas are only matched with an error of up to 15 ppmv (Fig. 4A). We tend to under-represent $\mathrm{PO}_{4}$ in equatorial areas (not shown) which is caused by our low resolution box model, in which high nutrient concentrations found in coastal upwelling regions can not be depicted properly. The depth gradients in the isotopic carbon records are fairly well reconstructed. Please remember, that an accurate rep- resentation of $\Delta^{14} \mathrm{C}$ was one of our criteria for model finetuning. $\quad \delta^{13} \mathrm{C}$ data [Kroopnick, 1985] show smallest values $(0.0-0.5 \% 0)$ in the deep Pacific, while in other deep ocean basins $\delta^{13} \mathrm{C}$ varies approximately between $0.5-1.0 \%$. Surface values are around 1.5-2.0\% . These distributions are all covered in our reference run.

\section{Time dependent changes}

In the following we identify the impacts of different processes on the atmospheric carbon records as summarized in Table 2. We start with short descriptions of individual processes and explain our assumptions on their implementations in the model. The temporal evolution of the carbon cycle including all these processes during Termination I will be covered in the next section. Considered here are changes in temperature, sea level, sea ice cover, ocean circulation, marine and terrestrial biosphere, weathering inputs, sediment/deep ocean exchange of alkalinity and carbon and coral reef growth. They are all first analyzed individually in the absence of any other processes such as $\mathrm{CaCO}_{3}$ compensation. We will highlight how current theories on causes of G/IG changes agree or conflict with the observations. Only from the analysis of a combination of all these time-dependent processes a conceptual understanding of the underlying causes of observed changes in the carbon cycle emerges. We finally attempt to explain the temporal evolution during the course of Termination I. All transient simulations covering Termination I were spun up for $30 \mathrm{kyr}$ to reach steady state, then started at $\mathrm{t}=26 \mathrm{kyr}$ BP and subsequently forced as described below using measured data sets (Fig. 6). The long spin up time is necessary to obtain steady states in ${ }^{14} \mathrm{C}$.

Atmospheric $p \mathrm{CO}_{2}$ during the last termination was measured most accurately on the EPICA Dome $\mathrm{C}$ ice core (EDC) [Monnin et al., 2001]. Data on the stable carbon isotope $\delta^{13} \mathrm{C}$ are hitherto only available from the Taylor Dome (TD) ice core [Smith et al., 1999], while $\Delta^{14} \mathrm{C}$ data sets exist back to 15.5 kyr BP from INTCAL98 [Stuiver et al., 1998] and measurements on ocean sediments from the Cariaco basin extending further back in time [Hughen et al., 2004]. These are our target records which should be interpreted in our modeling study (Fig. 5).

For our modeling experiment we ultimately need all proxy records on the same time scale. We have chosen to synchronize all ice core archives to the time scale of the annual layer counted Greenland GISP2 ice core [Meese et al., 1997] and use the starting and end points of the three fast regime shifts in $\mathrm{CH}_{4}$ (LGM-Bølling-Allerød (BA), BA-Younger Dryas (YD), YD-Holocene) as tie points for the synchronization of EDC and GISP2 and linearly interpolate between them. Due to a lack of a further tie point before $15 \mathrm{kyr}$ BP, the data records of EDC during the first half of the termination are shifted on the GISP2 age scale based on the LGM-BA transition only. Thus, the relative timing of the records at the beginning of the termination might be most uncertain, but $\mathrm{CH}_{4}$ records of GISP2 and EDC are still in good agreement (Fig. 6). Due to these missing $\mathrm{CH}_{4}$ tie points at the beginning 
of the termination and simultaneous measurements of $p \mathrm{CO}_{2}$ and $\delta^{13} \mathrm{C}$ on the TD ice core the TD $\delta^{13} \mathrm{C}$ is best synchronized via $p \mathrm{CO}_{2}$ to EDC and than to GISP2. The uncertainty in $\mathrm{TD} p \mathrm{CO}_{2}$ is $3 \mathrm{ppmv}(2 \sigma)$, which gives a synchronization uncertainty of the TD $\delta^{13} \mathrm{C}$ of about $150 \mathrm{yr}$ during times of fast changes in $p \mathrm{CO}_{2}$ (onset of $p \mathrm{CO}_{2}$ rise and YD), 375 years during the Heinrich I event, and rather uncertain timing in periods of stable $p \mathrm{CO}_{2}$ values (LGM, BA, Holocene). The main uncertainty in the dating of the ice core records is the gas age - ice age difference which increases with depth and is of the order of at least 500 years during the transition [Monnin et al., 2001]. Avoiding to imply an unfounded phase relationship between ice and sediment records, the latter are used on their own time scale. The age uncertainty in sediment records calibrated with AMS ${ }^{14} \mathrm{C}$ is of the order of 150 yr [Visser et al., 2003], but highly depends on the assumed reservoir correction for ${ }^{14} \mathrm{C}$. Data sets from highly fluctuating records were used after low-pass filtering using a $500 \mathrm{yr}$ running mean (see Fig. 6).

\subsection{Sea level, temperature, and sea ice}

Sea level changes deduced from coral reef terraces [Fairbanks, 1990] influence directly the salinity and concentrations of all oceanic tracers but also volumes and areas of the ocean boxes (Fig. 6). The rise in sea level by $85 \mathrm{~m}$ between 20 and $10 \mathrm{kyr}$ BP leads to a decrease in salinity by $2.3 \%$. As a consequence $p \mathrm{CO}_{2}$ will fall by about 12 ppmv (6 ppmv in combined scenarios where all processes are changed simultaneously) without any relevant impact on the carbon isotopes (Figs. 7A,B).

We use the isotopic temperature proxies of the GISP2 $\delta^{18} \mathrm{O}[$ [Grootes and Stuiver, 1997] and EDC $\delta \mathrm{D}[$ [Jouzel et al. , $2001]$ ice core records as proxies for the temporal evolution of sea surface temperature (SST) in the Northern North Atlantic and the Southern Ocean respectively, and rescale its G/IG amplitude $(\Delta \mathrm{T}=4 \mathrm{~K})$ to avoid the SST below sea water freezing point [e.g. Pflaumann et al., 2003; Becquey and Gersonde, 2003] (Fig. 6). Changes in equatorial SST with a maximum amplitude of about $3.75 \mathrm{~K}$ are taken from observations in foraminiferal proxy records [Visser et al., 2003]. This amplitude is larger than previous estimates of the G/IG rise in equatorial temperature [CLIMAP, 1976], but consistent with other recent studies [e.g. Aeschbach-Hertig et al., 2000; Lea et al., 2000; Nürnberg et al., 2000; Guilderson et al., 2001]. Temperature changes in the intermediate boxes follow those of the underlying deep sea boxes with G/IG amplitudes between 20 and $10 \mathrm{kyr}$ BP of 1.9 to $2.4 \mathrm{~K}$ forced by data sets from Labeyrie et al. [1987], recently confirmed by Martin et al. [2002].

Rising ocean temperatures add an increase of $32 \mathrm{ppmv}$ (17 ppmv in combined scenarios, Table 2, Fig. 7A). For the impact of temperature on $\delta^{13} \mathrm{C}$ not only changing reservoir sizes of atmospheric and oceanic carbon pools have to be considered, but the fractionation during gas exchange between atmosphere and surface ocean also depends directly on temperature (Fig. 7B) leading to an overall increase in $\delta^{13} \mathrm{C}$ of $0.4 \%$ in the course of the transition. It might be argued that the data sets and here especially the ice core records taken as temperature proxies are not representative for the selected ocean basins. For the Southern Ocean the regional aspect of Antarctic ice core temperature was recently confirmed [Becquey and Gersonde, 2003], but a lag of continental Antarctic temperature and SST of the oceanic moisture source regions might exist [Stenni et al., 2001]. The detailed choice of equatorial temperature proxies is of minor importance, because half of the simulated changes in $p \mathrm{CO}_{2}$ are caused by Southern Ocean temperature rise, one fourth by the North Atlantic and only about one tenth by the change in SST in each of the equatorial reservoirs.

New proxy studies find LGM Southern Ocean sea ice cover of approximately twice the size of today in winter and a remarkable glacial increase in the Atlantic section of the Southern Ocean in summer [Crosta et al., 1998a,b; Gersonde et al., 2005]. In the Northern Hemisphere summer sea ice seemed to be far more restricted than proposed previously [CLIMAP, 1976; Sarnthein et al., 2003]. Thus, we assume annual averaged sea ice areas during the LGM of 14 and 22 $\times 10^{12} \mathrm{~m}^{2}$ for the Northern and Southern Hemisphere, respectively. The temporal evolution of the sea ice area is coupled to local temperature proxies of GISP2 and EDC. Its direct influence on the gas exchange rates between atmosphere and surface ocean contributes a reduction of $2-5 \mathrm{ppmv}$ to the evolution of $p \mathrm{CO}_{2}$ (Fig. 7A), its amplitude depending on single or combined process analysis (Table 2 ).

The impact of sea ice and thus gas-exchange on $p \mathrm{CO}_{2}$ is strongly model dependent [Archer et al., 2003]. Furthermore, previous studies focused on the sea ice cover in the Southern Ocean [Stephens and Keeling, 2000; MoralesMaqueda and Rahmstorf, 2001], and suggested it to be a cause for the observed rise in $\mathrm{G} / \mathrm{IG} p \mathrm{CO}_{2}$. We note that our data-based assumption of sea ice variations in the South (which in the preindustrial setting is a source for atmospheric $\mathrm{CO}_{2}$ ) does impact only marginally on $p \mathrm{CO}_{2}$, but the contribution from the North (a sink for $\mathrm{CO}_{2}$ ) reduces $p \mathrm{CO}_{2}$ during the transition. Here, the sea ice covers increase from their preindustrial values of 50\% and 13\% in the North Atlantic and Southern Ocean, respectively, to $85 \%$ and $30 \%$ during the LGM. The sea ice effect is large in box models, when a surface box is nearly fully covered by sea ice and gas exchange is thus prevented. This was also the case in the study of Stephens and Keeling [2000].

\subsection{Ocean circulation}

Based on observational estimates and modeling studies, the North Atlantic Deep Water (NADW) formation is assumed to be reduced [Curry et al., 1988; Duplessy et al., 1988] by about $40 \%$ of its modern strength to $10 \mathrm{~Sv}$ during glacial times [Winguth et al., 1999; Meissner et al., 2003] and completely shut-off during Heinrich $(\mathrm{H})$ events [Alley and Clark, 1999; Schulz et al., 2001; Rahmstorf, 2002; Knutti et al., 2004; McManus et al., 2004]. In the YD cold event (approximately $13-11.8 \mathrm{kyr}$ BP) NADW formation is not shut-down completely, but reduced by $15 \%$ [McManus et al., 2004]. The THC is resumed at the beginning of the warming into the BA [Charles and Fairbanks, 1992] to intermediate strength of 13 $\mathrm{Sv}$, since ongoing freshwater from melting inland ice sheets 
to the North Atlantic still reduces the strength of NADW formation [Knorr and Lohmann, 2003] (Fig. 6).

The reduction of NADW formation by $40 \%$ leads to a decrease in glacial $p \mathrm{CO}_{2}$ by $12 \mathrm{ppmv}$. The sharp decrease of NADW formation at the beginning of the Heinrich event 1 and the YD reduces $p \mathrm{CO}_{2}$ further by 8 and 6 ppmv, respectively (Fig. 8A). This massive and abrupt collapse and rapid resumption of the Atlantic meridional circulation was concluded from ${ }^{231} \mathrm{~Pa} /{ }^{230} \mathrm{Th}$ data [McManus et al., 2004]. These authors also find only a small decline in the Atlantic overturning during the YD cold event. This supports our assumption of only little changes in NADW here and is in contrast to former studies, which attempted to explain the well pronounced peak in atmospheric $\Delta^{14} \mathrm{C}$ during the YD with a complete shutdown of deep water formation [e.g. Stocker and Wright, 1996; Delaygue et al., 2003]. However, as the ${ }^{231} \mathrm{~Pa} /{ }^{230} \mathrm{Th}$ data carry a mixed information of both export production and ocean circulation only the times of fast changes in the circulation patterns can be identified, while the quantification of changes in the THC is difficult.

Southern Ocean stratification is assumed to collapse at about $17 \mathrm{kyr}$ BP leading to enhanced vertical mixing, in line with oceanic $\delta^{13} \mathrm{C}$ data [Spero and Lea, 2002; Hodell et al., 2003]. We like to emphasize that the variation of vertical mixing rates as plotted in Fig. 6 still allows water mass exchange between Southern Ocean surface and deep waters during glacial conditions. Prior to $17 \mathrm{kyr}$ BP when the vertical mixing in the Southern Ocean was set to $0 \mathrm{~Sv}$, there still exists an upwelling of $16 \mathrm{~Sv}$ (if NADW formation is unchanged) and a downwelling of $9 \mathrm{~Sv}$ in the Southern Ocean (Fig. 2). Further evidence for a reduced glacial Southern Ocean vertical mixing comes from nutrient records [François et al., 1997; Crosta and Shemesh, 2002]. Two modeling approaches [Gildor et al., 2002; Paillard and Parrenin, 2004] on long-term variability of atmospheric $p \mathrm{CO}_{2}$ also pinpoint G/IG changes in Southern Ocean vertical mixing as one dominant process important for late Quaternary climate change. While both studies propose a physical mechanism for this increase in Southern Ocean water colum stratification, they differ in detail. Gildor et al. [2002] propose that during glacial times the cooler NADW arriving in the Southern Ocean reduces the rate of vertical mixing there. Paillard and Parrenin [2004] explain glacial deep stratification in the Southern Ocean by more saline and thus denser bottom waters which involves brine rejection and is linked to sea ice formation and the Antarctic ice-sheet extent.

The breakdown of the Southern Ocean stratification would lead to the release of $37 \mathrm{ppmv}$ of $p \mathrm{CO}_{2}$ and a drop in $\delta^{13} \mathrm{C}$ by $0.25 \%$ (Fig. 8). However, whether the increase in vertical mixing in the Southern Ocean happens rapidly or over several millenia is of importance for the temporal evolution of the signals (see section 6.1). We can not reproduce the sharp decrease in atmospheric $\delta^{13} \mathrm{C}$ around $17 \mathrm{kyr}$ BP if the Southern Ocean vertical mixing rates is, for example, linearly coupled to the temporal evolution of SST (scenario SO $=\mathrm{f}(\mathrm{SST})$ in Fig. 8).

\subsection{Biological pump}

The preindustrial biological pump strength of $10 \mathrm{PgC}_{\mathrm{yr}}-1$ reduces atmospheric $p \mathrm{CO}_{2}$ already by more than $200 \mathrm{ppmv}$ compared to an abiotic ocean [e.g. Broecker and Peng, 1986]. As shown in other studies, iron fertilization of glacial marine productivity [Martin, 1990] might contribute to $5-45 \mathrm{ppmv}$ of the G/IG change in $p \mathrm{CO}_{2}$ [Watson et al., 2000; Ridgwell and Watson, 2002; Bopp et al., 2003; Ridgwell, 2003b]. If $\mathrm{G} / \mathrm{IG}$ changes in marine export production are assumed to depend on iron $(\mathrm{Fe})$ fertilization, then they are restricted to HNLC regions. The main HNLC areas are the Southern Ocean and the North Pacific, but the latter is only of secondary importance here due to its small extent and the low macro-nutrient concentration in comparison to the Southern Ocean [Conkright et al., 1994; Röthlisberger et al., 2004]. To simulate an aeolian Fe fertilization of the Southern Ocean we take the non-sea-salt-Ca ${ }^{2+}$-ion concentration (nss-Ca ${ }^{2+}$ ) in EDC [Röthlisberger et al., 2002] as proxy for aeolian dust and thus iron input in the Southern Ocean, which might enhance the marine export production if the macro-nutrient concentrations allow an increased productivity. The rise in $p \mathrm{CO}_{2}$ starts not before $18 \mathrm{kyr} \mathrm{BP}$. We therefore assume an iron unlimited enhanced export productivity in the Southern Ocean prior to $18 \mathrm{kyr} \mathrm{BP}$ of $6.4 \mathrm{PgC} \mathrm{yr}^{-1}$ (scenario export production variation only), which consumes all available macro nutrients there. After $18 \mathrm{kyr}$ BP the Southern Ocean marine export production decreases over time towards its preindustrial flux of $3.4 \mathrm{PgC} \mathrm{yr}^{-1}$ parallel to the $\mathrm{nss}-\mathrm{Ca}^{2+}$ decrease.

The proxy nss- $\mathrm{Ca}^{2+}$ limits the impact of Fe to times before $16 \mathrm{kyr} \mathrm{BP}$, when nss- $\mathrm{Ca}^{2+}$ is higher by two orders of magnitude than in the time interval between $16-10 \mathrm{kyr}$ BP (Fig. 6 ). If the available macro nutrients in the Southern Ocean are fully exploited, the glacial export production is $30 \%$ (17\% in combined scenarios including all processes) larger than its preindustrial value (Fig. 9A). This corresponds to a reduction of approximately $20 \mathrm{ppmv}$ in $p \mathrm{CO}_{2}$ consistent with other modeling studies [Ridgwell, 2003b] and a sharp decrease in atmospheric $\delta^{13} \mathrm{C}$ by $0.15 \%$ (Figs. 9A,B). As marine production always depends on the availability of preformed macronutrients, this result is tightly coupled to ocean circulation and the upwelling of re-mineralized nutrients from the deep ocean.

The question whether marine export production in the Southern Ocean was largely increased during glacial times is highly debated based on nitrogen-isotopes as proxy of nutrient utilization, comparisons of benthic and planktic $\delta^{13} \mathrm{C}$ and other geochemical tracers [e.g. Duplessy et al., 1988; Charles and Fairbanks, 1990; Kumar et al., 1995; François et al., 1997; Anderson et al., 1998, 2002; Frank et al., 2000; Moore et al., 2000; Bopp et al., 2003; Chase et al., 2003; Kohfeld et al., 2005]. Interpretations varied largely in the past. For example, an increased glacial export of organic carbon in the Southern Ocean of about $3 \mathrm{PgC} \mathrm{yr}^{-1}$ was concluded from an ecosystem based study [Moore et al., 2000] proposing an alternative interpretation of the data presented by François et al. [1997] who supported surface-water stratification in the Southern Ocean as most important process 
impacting on the carbon cycle. It is generally agreed that export production south of the Antarctic Polar Front (APF) decreased during glacial times [François et al., 1997; Anderson et al., 1998, 2002; Frank et al., 2000]. The spatial extent of an increased glacial export north of the APF, however, is so far not verified. Data from the Pacific sector of the Southern Ocean [Chase et al., 2003] indicate that the increase in export production found in the Atlantic and Indic sectors [François et al., 1997; Anderson et al., 1998] might not be applicable to other areas. The overall increased export production might be smaller as previously estimated, but was certainly spatially heterogeneous. Data are especially sparse in the largest section of the Pacific sector. It should be noted that our Southern Ocean boxes include the whole ocean area south of $40^{\circ} \mathrm{S}$ covering also large areas north of the APF. The controversy on glacial Southern Ocean export production is not yet resolved. However, the rise in the integrated glacial export production south of $40^{\circ} \mathrm{S}$ assumed here appears to be at least consistent with proxy evidence. The determination of its final magnitude still requires further research.

From sediment trap data there is evidence for a coupling of organic and inorganic matter in the sinking particles [Klaas and Archer, 2002; Passow, 2004]. Although the detailed ratio of the exported matter at $100 \mathrm{~m}$ water depth can not be deduced from these studies, they indicate a fairly constant ratio and we therefore do not consider changes in the rain ratio $\left(r=\mathrm{C}_{\text {org }}: \mathrm{CaCO}_{3}\right)$ in our standard scenarios, but estimate the impacts of its variation in the following. The range of the rain ratio found in the literature $(r=4-17)$ [e.g. Archer and Maier-Reimer, 1994; Sigman et al., 1998; Sarmiento et al., 2002] would allow an increase of $15 \mathrm{ppmv}$ $(r=4)$, or a decline of less $10 \mathrm{ppmv}(r=17)$ in our preindustrial standard scenario (Fig. 3B). One has to keep in mind that in other studies the rain ratio differed between low and high latitudes. Different rain ratios might also be based on different export production fluxes of organic matter. Furthermore, it was hypothesized that a shift in phytoplankton communities from carbonate producing coccolithophores to non-calcifying diatoms might have occurred during glacial times in the Southern Ocean and elsewhere [Brzezinski et al., 2002; Matsumoto et al., 2002]. This would weaken the carbonate pump and change the rain ratio. We estimated the maximum impact of this hypothesis in our modeling context. If we assume that the additional glacial export produc-


the rain ratio would rise from 10:1 to $13: 1$, lowering glacial $p \mathrm{CO}_{2}$ further by less than $8 \mathrm{ppmv}$. This difference in $p \mathrm{CO}_{2}$ caused by rain ratio adjustment does not depend on dissolution/sedimentation effects.

It is important to note the water depth at which both export and rain ratio are considered since vertical fluxes of organic matter and $\mathrm{CaCO}_{3}$ are subject to remineralization in the water column. Since some of our surface ocean boxes have a depth of $1000 \mathrm{~m}$ we recalculate fluxes to $100 \mathrm{~m}$ water depth, which is most widely used in field surveys.

\subsection{Terrestrial carbon pools}

The terrestrial parts of the BICYCLE model and possible forcing were investigated in detail in a different study [Köhler and Fischer, 2004]. We therefore keep descriptions here very brief. Global area available for land vegetation is calculated from sea level. The residual of competing processes (area loss due to flooding and area gain due to a retreat in land ice sheets) is a vegetation area which is $\sim 5 \times 10^{12} \mathrm{~m}^{2}$ smaller at the LGM than at preindustrial times [Adams and Faure, 1998]. Additionally, the growth of terrestrial biomass is affected by $\mathrm{CO}_{2}$ and average temperature. To use all boundary conditions available for the $\mathrm{G} / \mathrm{IG}$ transition $\mathrm{CO}_{2}$ fertilization is implemented in a first step in a semi-coupled way, where vegetation growth is calculated as function of prescribed $p \mathrm{CO}_{2}$ measured in ice cores and not of the internally calculated atmospheric $p \mathrm{CO}_{2}$. Thus, the output of the terrestrial part can be understood as another boundary condition for the ocean/atmosphere module. In the fully-coupled mode any offset in the simulations from the $p \mathrm{CO}_{2}$ data will be amplified due to the $\mathrm{CO}_{2}$ fertilization of the biosphere making a reconstruction of atmospheric carbon over longer times extremely difficult. Global average temperature seen by the terrestrial module is a 3:1 mixture (corresponding to the latitudinal land area distributions in which $3 / 4$ of the global land area (excluding Antarctica) is located in the Northern Hemisphere) of GISP2 and EDC temperature proxy with G/IG amplitudes of $8 \mathrm{~K}$ and $5 \mathrm{~K}$ in the Northern and Southern Hemisphere, respectively [Kutzbach et al., 1998; Kageyama et al., 2001; Kim et al., 2002]. Thus, the terrestrial carbon stocks increase from about $1650 \mathrm{PgC}$ at the LGM to $2200 \mathrm{PgC}$ in the late Holocene, but the parameterization of this transition still allows various different forcing combinations. Therefore, the results of simulations with parameter combinations used in Köhler and Fischer [2004] which either follow more a $\mathrm{CO}_{2}$ fertilization (TB1) or a climate induced change scenario (TB2) in the terrestrial carbon stock are averaged here. Alternatively (scenario TB0), the terrestrial biosphere grows by $530 \mathrm{PgC}$ from the LGM to preindustrial times with an assumed linear increase of 400 $\mathrm{PgC}$ between 18 and $11.8 \mathrm{kyr}$ with a constant fractionation factor of $-17 \%$. (Fig. 11A).

For an understanding of the regrowth of the terrestrial biosphere complex vegetation models are certainly more efficient tools than our model. However, with our simple sevenbox module of the terrestrial biosphere we can sketch the main idea of a possible build-up of additional carbon on land. While the total amount of carbon accumulated in the terrestrial pools in the course of the transition is well within the estimates of other studies [see review in Köhler and Fischer, 2004], the temporal evolution of the biosphere depends on the physiological response of the biosphere on climate and $p \mathrm{CO}_{2}$ changes.

In the null-model (scenario TB0), which assumes a linear growth of the terrestrial pools from LGM to the Holocene, atmospheric $p \mathrm{CO}_{2}$ decreases by 34 ppmv, neglecting $\mathrm{CaCO}_{3}$ compensation (Fig. 10A). In the combined scenario using the null-model for the terrestrial pools (A-TB0) the dynamic in $\delta^{13} \mathrm{C}$ can not be explained (Fig. 12). This highlights the 
importance of intrinsic dynamics in the terrestrial part of the carbon cycle. The main difference in the dynamics of TB1 and TB2 is the release of terrestrial carbon during the YD cold event, which leads to a peak of $p \mathrm{CO}_{2}$ around $13 \mathrm{kyr} \mathrm{BP}$, which is coupled to a drop in $\delta^{13} \mathrm{C}$ by $0.3 \%$ (Fig. 10A,B).

\subsection{Sediment/ocean fluxes and continental weathering}

Besides the amount of carbon transferred from the ocean to the biosphere, the timing and rate of change of the transfer are equally important for the transient response in deep ocean chemistry and atmospheric $p \mathrm{CO}_{2}$. For example, the transfer of carbon between ocean and biosphere triggers carbonate compensation in the deep sea which in turn affects the time evolution of atmospheric $p \mathrm{CO}_{2}$. Carbonate compensation is a response to changes in $\left[\mathrm{CO}_{3}^{2-}\right]$ in the deep ocean. To counteract these fluctuations in $\left[\mathrm{CO}_{3}^{2-}\right]$, the saturation horizon of $\mathrm{CaCO}_{3}$ varies, sedimentation or dissolution rates of $\mathrm{CaCO}_{3}$ change, and deep ocean $\left[\mathrm{CO}_{3}^{2-}\right]$ and atmospheric $p \mathrm{CO}_{2}$ establish a new equilibrium [Broecker and Peng, 1987]. We implement sedimentation and dissolution as fluxes of DIC and ALK between the deep ocean and the sediment in our model as follows: We use the current knowledge on shallowing/deepening of the lysocline during Termination I as another boundary condition. The lysocline is the oceanic depth below which sedimentary calcite dissolves. It has been shown that the lysocline during the LGM was about $800 \mathrm{~m}$ shallower in the Atlantic and Southern Ocean and $500 \mathrm{~m}$ deeper in the Indo-Pacific [Crowley, 1983; Peterson and Prell, 1985; Curry and Lohmann, 1986; Farrell and Prell, 1989; Howard and Prell, 1994]. We here assume that changes in the lysocline can be approximated by changes in the saturation depth of calcite defined by the intercept of the $\left[\mathrm{CO}_{3}^{2-}\right]$ profile in the deep ocean with the saturation concentration of calcite. Both $\left[\mathrm{CO}_{3}^{2-}\right]$ and the saturation concentration are a function of temperature, salinity, and pressure. While all state variables such as DIC and ALK and environmental parameters like temperature and salinity are assumed to be homogeneous within one ocean box, pressure and thus $\left[\mathrm{CO}_{3}^{2-}\right]$ and the saturation concentration vary with depth and are calculated here in steps of $200 \mathrm{~m}$ and interpolated in between. If the modeled saturation depth falls out of the range given by the observations additional $\mathrm{CaCO}_{3}$ is either dissolved or precipitated, increasing or decreasing deep ocean $\left[\mathrm{CO}_{3}^{2-}\right]$ and thus deepening or shoaling the saturation depth until observations are matched again by the model. Dissolution or precipitation involves the flux of one mol DIC and two mol ALK between ocean and sediment per one mol $\mathrm{CaCO}_{3}$ in the corresponding direction. Vertical gradients in temperature and salinity are very coarse here, a more accurate description which reproduces the observed gradients at a higher resolution might be possible with an advection-diffusion scheme [e.g. Zeebe, 2005].

In this first attempt the lysocline in each deep ocean box is assumed to change linearly with time between 18 and 11.8 kyr BP. The implementation of the sedimentation/dissolution mechanism covers the overall inventory changes of ALK in the ocean and carbon in the ocean-atmosphere-biosphere system. Thus, it includes implicitly impacts of a reduction in terrestrial weathering inputs of bicarbonate to theses inventories, whose reduced input over the course of the transition would result in an increase in $p \mathrm{CO}_{2}$ of the order of $9 \mathrm{ppmv}$ [Munhoven, 2002]. Our carbon cycle calculations are now based on an open system where alkalinity and DIC in the atmosphere-ocean-biosphere are not conserved anymore.

If we implement this dissolution/sedimentation mechanism in our model the modeled decrease in $p \mathrm{CO}_{2}$ caused by the terrestrial regrowth in scenario TB0 is reduced by $7 \mathrm{ppmv}$ due to $\mathrm{CaCO}_{3}$ compensation (Fig. 10A). In combined scenarios, including all time-dependent processes, the sedimentation/dissolution mechanism contributes 34 ppmv to the atmospheric rise in $p \mathrm{CO}_{2}$ during Termination I (Table 2). Even if the lysocline depths are held constant at their preindustrial levels, the changes in the deep ocean carbonate chemistry demand increasing sedimentation over the course of the transition (Fig. 11C) which is also in line with a modeling study on atmospheric ${ }^{14} \mathrm{C}$ [Beck et al., 2001]. The mean ocean alkalinity declines by about $5 \%$ and the carbon content of the ocean-atmosphere-biosphere is reduced by about $1000 \mathrm{PgC}$ as system response to changes in the global carbon cycle and especially the increased carbon storage on land (Fig. 11C). If on the other hand the amount of carbon accumulated in the terrestrial biosphere during the transition is larger than assumed here the carbonate compensation will counteract this (DGVMs [Kaplan et al., 2002] and other studies based on pollen reconstructions, $\delta^{13} \mathrm{C}$ budget analysis, and different modeling approaches [see overview in Köhler and Fischer, 2004] tend to propose a G/IG increase of up to $1000 \mathrm{PgC}$ ). If we compare a $\mathrm{G} / \mathrm{IG}$ rise of 500 and $1000 \mathrm{PgC}$ in terrestrial carbon storage in scenarios including $\mathrm{CaCO}_{3}$ compensation, the glacial $p \mathrm{CO}_{2}$ would be only $10 \mathrm{ppmv}$ higher in the case of the $1000 \mathrm{PgC}$ rise.

It is important to note that the treatment of $\mathrm{CaCO}_{3}$ compensation described above is rather simplistic. It represents a rough estimate of sedimentation/dissolution which is described more accurately (although computationally less efficient) by process-based models of early diagenesis. Due to ocean circulation it takes on the order of thousand years until atmospheric $p \mathrm{CO}_{2}$ reaches a new equilibrium as a response to changes in sedimentation/dissolution reactions. Changes in the depth of the lysocline which are thought to reflect a record of $\mathrm{CaCO}_{3}$ compensation over time are prescribed as boundary conditions. Thus, also the temporal evolution of $\mathrm{CaCO}_{3}$ compensation with a time scale of several millennia [Archer et al., 1998] is not a result of the internal dynamics of our model but prescribed. Fortunately, the temporal evolution of the lysocline is not critical to the model outcome as shown in combined scenarios (Fig. 11C).

Neritic carbonate deposition during coral reef build-up in shallow waters is another process of sediment/ocean interaction. Reef growth consumes $\mathrm{CaCO}_{3}$ and is a source for $\mathrm{CO}_{2}$ in surface waters and was proposed as one possibility to explain the $\mathrm{G} / \mathrm{IG}$ increase in atmospheric $p \mathrm{CO}_{2}$ [Berger, 1982]. According to a recent data based study [Vecsei and Berger, 2004] the massive shallow water accumulation of $\mathrm{CaCO}_{3}$ started after melt water pulse (MWP) 1A around 14 kyr BP where sea level rose to about $70 \mathrm{~m}$ below present and flooded huge shelf areas and, thus, can not contribute signifi- 
cantly to the observed $p \mathrm{CO}_{2}$ rise during the transition. However, most of the coral reef growth of an estimated $370 \mathrm{PgC}$ over the last $14 \mathrm{kyr}$ occurred during the Holocene, peaking around the early Holocene climate optimum ( $8-6 \mathrm{kyr}$ BP). The reef growth before $10 \mathrm{kyr}$ BP as proposed by Vecsei and Berger [2004] was tested with our model and the influence on $p \mathrm{CO}_{2}$ is less than 3 ppmv.

\section{Temporal evolution of the carbon cycle during Termi- nation I}

Combining all relevant processes simultaneously gives us three different realizations depending on the scenario for the regrowth of the terrestrial biosphere. At the LGM all scenarios start with the same carbon cycle conditions of $p \mathrm{CO}_{2}$ $=179$ ppmv, $\delta^{13} \mathrm{C}=-6.6 \%$, and $\Delta^{14} \mathrm{C}=393 \%$ (Table 3). Four clearly distinguishable intervals with different rates of change in atmospheric $p \mathrm{CO}_{2}$ were identified by Monnin et al. [2001]. A comparison of simulated and measured atmospheric carbon records over Termination I is compiled in Fig. 12.

\subsection{The onset of the rise in $p \mathrm{CO}_{2}$}

Interval I (18.0 - 16.5 kyr BP on the GISP2 time scale) with $p \mathrm{CO}_{2}$ increasing at a rate of $20 \mathrm{ppmv} \mathrm{kyr}^{-1}$ is accompanied by a drop of $0.5 \%$ in $\delta^{13} \mathrm{C}$ of atmospheric $\mathrm{CO}_{2}$ and a rather stable $\Delta^{14} \mathrm{C}$ during that time. Our simulations reproduce the timing and the smooth increase in $p \mathrm{CO}_{2}$ at the onset of the transition if we consider Fe fertilization in the Southern Ocean as a process for increased biological productivity and, thus, reduced atmospheric $p \mathrm{CO}_{2}$ in the LGM. However, since the drop in nss- $\mathrm{Ca}^{2+}$, which we use as a proxy for $\mathrm{Fe}$ input into the Southern Ocean, starts already one kyr earlier than the $p \mathrm{CO}_{2}$ increase, Fe seems not to be the limiting factor before $18 \mathrm{kyr} \mathrm{BP}$ and the biological pump in the Southern Ocean implies the existence of a threshold in the aeolian $\mathrm{Fe}$ supply rate as already hypothesized previously for Termination II [Broecker and Henderson, 1998]. If nss-Ca ${ }^{2+}$ and, thus, aeolian $\mathrm{Fe}$ input are above this threshold prior to 18 kyr BP the export production in the Southern Ocean is not limited by $\mathrm{Fe}$ in the model. Only if both the nss- $\mathrm{Ca}^{2+}$ and Fe supply fall below this threshold, i.e. implying a reduction in nss- $\mathrm{Ca}^{2+}$ by one order of magnitude, Fe becomes the limiting factor of Southern Ocean productivity and progressively more so in the scenario with the further reduction in nss- $\mathrm{Ca}^{2+}$ during the following 2 kyr. This threshold below which a reduction in organic export is globally detectable in increasing $p \mathrm{CO}_{2}$ might be simply a switch from macro nutrient limitation (prior to $18 \mathrm{kyr} \mathrm{BP}$ ) to iron limitation thereafter.

Our simulations reveal that within interval I only the changes in marine export production together with a breakdown of salinity driven [Adkins et al., 2002] stratification of the Southern Ocean bringing old, thus, isotopically light carbon to the surface can produce the strong signal in the atmospheric $\delta^{13} \mathrm{C}$ (Figs. 8A,B). Further evidence on the changes in Southern Ocean stratification stems from nutrient records [François et al., 1997] and the G/IG change in $\delta^{13} \mathrm{C}$ in benthic foraminifera in the deep Southern Ocean of $1.4 \%$ [Hodell et al., 2003] which our model only reproduces with the assumed abrupt rise in Southern Ocean ventilation around 17 kyr BP (Fig. 11B). We suggest a retreat in winter sea ice in the Southern Ocean as the main cause of the breakdown in Southern Ocean stratification. The reduced melting of salt depleted sea ice in the sea ice export regions leads to less fresh surface waters in these areas. On the other hand, the production of salty bottom water due to brine rejection during sea ice formation close to the Antarctic continent should be reduced, jointly leading to a destabilization of the water column. Effectively, this process together with any strengthening of wind-drag induced mixing of previously sea ice covered areas acts as an amplifier of any sea ice effect on gas exchange rates [Stephens and Keeling, 2000].

\subsection{Heinrich event 1}

According to a modeling study [Knorr and Lohmann, 2003] the reduction in Southern Ocean winter sea ice acts as a flywheel for the time-delayed resumption of the THC through an increased mass transport of surface waters into the southern Atlantic Ocean. Thus, we assume an increased NADW formation at the end of interval II $(16.5-15.0 \mathrm{kyr} \mathrm{BP}$, approximately similar to Heinrich event 1 ) in which the changing rate in $p \mathrm{CO}_{2}$ slows down to $8 \mathrm{ppmv} \mathrm{kyr}^{-1}$, an increase in $\delta^{13} \mathrm{C}$ of $0.4 \%$ occurs, while the radiocarbon signature decreases sharply at the end of this interval. In detail, NADW formation is shut-off during the Heinrich event [Rahmstorf, $2002]$, but resumes to an intermediate strength (13 Sv) thereafter (Fig. 6). We are aware that Heinrich event 1 was probably shorter than interval II. According to a recent published review [Hemming, 2004] Heinrich event 1 started around $16.8 \mathrm{kyr}$ BP with a duration of $288-1410 \mathrm{yr}$, depending on the observed sediment core. Within the age uncertainty of the ice core records the starting time of interval II (16.5 kyr BP) falls together with the start of Heinrich 1 . However, from the data based estimate of changes in Atlantic meridional overturning a reduced deep water formation in the North Atlantic very likely exceeds Heinrich 1 until the beginning of the BA warm interval [McManus et al., 2004]. The second main process during interval II which we detect as cause for the increase in the atmospheric carbon isotopic signature is the beginning growth of isotopically light biomass on land (Figs. 10B, 11A).

\subsection{Bølling-Allerød}

Between 15 and $13 \mathrm{kyr}$ BP (BA and interval III) a rather constant atmospheric $p \mathrm{CO}_{2}$ concentration of $238 \pm 1 \mathrm{ppmv}$ is met by a slow decrease in its isotopic signature $(-0.2 \%)$, while $\Delta^{14} \mathrm{C}$ stays constant in the INTCAL98 record, but decreases with time in the Cariaco basin record. Northern hemispheric cooling into the YD is expected to result in a reduction in terrestrial carbon stocks and leads to the drop in the isotopic carbon signal (Figs. 10B, 11A) in our model in line with the ice core record. The BA warm interval is accompanied by a cooling in the South during the Antarctic Cold Reversal as seen in the EDC $\delta$ D record (Fig. 6) [Stenni et al., 2001] with only little impact on the atmospheric carbon records. 


\subsection{Younger Dryas}

In the final interval (13.0-11.8 kyr BP) of Termination I consisting of the $\mathrm{YD}, p \mathrm{CO}_{2}$ increases again at a rate of $20 \mathrm{ppmv}$ $\mathrm{kyr}^{-1}$. This is accompanied by first constant and then rising $\delta^{13} \mathrm{C}$ by $0.4 \%$. The increase in $\delta^{13} \mathrm{C}$ starts in the middle of the $\mathrm{YD}$ and is extended $1 \mathrm{kyr}$ into the Holocene. However, the $\delta^{13} \mathrm{C}$ signal fluctuates within its uncertainty at the end of the YD which makes the exact termination of its rise difficult. Radiocarbon is rising sharply at the beginning of the YD, then falling again. We propose only a small change in ocean circulation during the $\mathrm{YD}$, supported by our modeled $p \mathrm{CO}_{2}$ and $\delta^{13} \mathrm{C}$ (Fig. 12). This implies that observed fluctuations in atmospheric $\Delta^{14} \mathrm{C}$ have to be related to changes in the ${ }^{14} \mathrm{C}$ production rate at that time and can not be explained by changes in DWP. The estimate of ${ }^{14} \mathrm{C}$ production rates used here is based on geomagnetic field fluctuations [Laj et al., 2002] — used recently by Hughen et al. [2004] — and agrees for the last $18 \mathrm{kyr}$ with rates calculated from the ${ }^{10} \mathrm{Be}$ record found in ice cores [Muscheler et al., 2004], but uncertainties in both methods of $\pm 10 \%$ (relative error) are still large. A shutdown in NADW formation during the YD would explain about half of the observed peak of $100 \%$ in $\Delta^{14} \mathrm{C}$ and result in an increase in $\delta^{13} \mathrm{C}$ by $0.2 \%$ and in a decrease in $p \mathrm{CO}_{2}$ by $20 \mathrm{ppmv}$ in our model, the latter two are variations which are not found in the ice core records during interval IV (scenario A-TB0YD, Fig. 12). Other modeling studies using a zonally averaged global ocean circulation model [Marchal et al., 1998b, 1999, 2001] simulate the YD as a meltwater pulse induced cooling in the North Atlantic. These authors are also not able to explain the observed peak in $\Delta^{14} \mathrm{C}$, but their simulated anomaly of rising $p \mathrm{CO}_{2}$ during the cold event is in line with the ice core data. The dynamics in the simulated $p \mathrm{CO}_{2}$ in these studies are caused by changes in NADW formation, temperature, and marine export production, as these processes were not uncoupled. Their rise in $p \mathrm{CO}_{2}$ during the YD was mainly caused by the reduced marine productivity caused by nutrient depletion in the North Atlantic.

Our modeling results of the $\delta^{13} \mathrm{C}$ increase at about $12 \mathrm{kyr}$ $\mathrm{BP}$ is composed of two different steps of $+0.2 \%$ within and $+0.1 \%$ shortly after the YD. This differs somewhat from the TD data of first constant $\delta^{13} \mathrm{C}$ followed by a rise of $0.4 \%$ during in the end of the YD. The first step falls together with warming in the Southern Ocean and $\mathrm{CO}_{2}$ fertilized regrowth of terrestrial carbon stocks during the YD. Temperature dependent fractionation during gas exchange contributes mostly to this signal (Fig. 7B). Note, that the phasing is highly dependent on the record used for SST in the Southern Ocean. If, e.g. the Southern Ocean temperature derived from the EDC deuterium record is replaced by the deuterium excess record from the same ice core [Stenni et al., 2001] representing moisture source temperatures at about $40^{\circ} \mathrm{S}$ then this difference in modeled versus observed $\delta^{13} \mathrm{C}$ would be resolved. The second step is due to the main increase in terrestrial biomass during the Northern hemispheric warming. A concurrent strengthening of the THC reduces the rise in $\delta^{13} \mathrm{C}$ after the YD to about half of its original size (from +0.2 to $+0.1 \%$ ). An increase in the terrestrial biomass by $250 \mathrm{PgC}-$ about half of the proposed G/IG increase in the terrestrial carbon stocks - over less than $1 \mathrm{kyr}$ is necessary (and according to our model possible, see Figs. 10B, 11A) for a rise of more than $+0.2 \%$ in atmospheric $\delta^{13} \mathrm{C}$. Accordingly, our model suggests that the terrestrial biosphere depends more on climate (scenario A-TB2) than on $\mathrm{CO}_{2}$ fertilization effects (A-TB1) on G/IG time scales (Fig. 12). However, since our biospheric module does not incorporate spatially resolved aspects the impact of land flooded by sea level rise and the regrowth of boreal forests and tundra in the North after the retreat of the continental ice sheets might be underestimated. Here, only the effect that the land area available for vegetation was about $4 \%$ smaller at the LGM than at preindustrial times was incorporated [Köhler and Fischer, 2004] while the Lund-Potsdam-Jena DGVM calculated that the potential regrowth of the biosphere after the ice retreat was $200 \mathrm{PgG}$ higher than carbon losses on land due to flooding during the time of the transition [Joos et al., 2004]. Furthermore, these two opposing processes might have been time delayed. Our study nevertheless indicates that fast fluctuations in climate including the YD cold event need to be considered if the G/IG changes in terrestrial carbon are investigated, thus asking for improvements in previous studies [Kaplan et al., 2002; Joos et al., 2004]. In a case study investigating a meltwater flux experiment of 500 years length to the North Atlantic and its subsequent cooling of the Northern Hemisphere the terrestrial carbon pools lose $180 \mathrm{PgC}$ [Scholze et al., 2003]. Results of climate change induced by freshwater discharge experiments on the terrestrial carbon storage in the setting of Joos et al. [2004] suggest that the amplitude in carbon storage anomaly might be smaller [Köhler et al., 2005].

\section{Discussion}

\subsection{When time matters}

This study is an improvement over many steady state simulations done in the past. So far, it was concluded from an inverse modeling study analyzing steady state simulations of a carbon cycle box model with seven oceanic boxes that uncertainties in proxy data and models are still too large to confidently chose one scenarios responsible for observed variations in $p \mathrm{CO}_{2}$ [LeGrand and Alverson, 2001]. By introducing the time domain as a fourth target dimension beside $p \mathrm{CO}_{2}, \delta^{13} \mathrm{C}$, and $\Delta^{14} \mathrm{C}$ our transient modeling approach (in contrast to steady state simulations) is capable of disentangling the effects of various processes operating on the global carbon cycle on $\mathrm{G} / \mathrm{IG}$ timescales. However, as soon as the time domain becomes important, the robustness of our interpretation also depends also on the quality of the synchronization of various records on the same age scale. In the following we therefore discuss some aspects of age uncertainty imprinted in the paleo records and of the timing of certain processes.

The Taylor Dome $\delta^{13} \mathrm{C}$ is arguably the least reliable data set used here in terms of age constraint and uncertainty. Therefore, our interpretation has to be understood as a rough estimate of the impacts of various processes on the carbon cycle. Especially the timing of the oceanic reorganization 
which we deduce from modeling based assumptions and the reproduction of our target records might be taken with caution. For example, the timing of the stratification breakdown in the Southern Ocean might vary by about \pm 500 yr. From the sequence of events explaining the resumption of ocean circulation during the transition [Knorr and Lohmann, 2003] a delay of about $2 \mathrm{kyr}$ of the abrupt strengthening of the THC around $15 \mathrm{kyr}$ BP after the Southern Ocean sea ice retreat was proposed. As this sea ice retreat is directly connected with the stratification breakdown it seems not likely that the onset of the $p \mathrm{CO}_{2}$ increase $3 \mathrm{kyr}$ prior to the THC resumption at approximately $18 \mathrm{kyr}$ BP was initialized by Southern Ocean vertical mixing, but it can not be excluded due to the uncertainties of the age scales of the ice cores and our model. Eventually, new $\delta^{13} \mathrm{C}$ records with high temporal resolution to be derived from the new EPICA ice cores [e.g. Leuenberger et al., 2003] will resolve finer structures and may lead to an improved interpretation of changes in the carbon cycle over G/IG time scales. However, first results from the EPICA ice cores show high data scatter likely related to the enclosure process of the air bubbles which make it difficult to reproduce known patterns of other ice cores leaving the question of data uncertainty still open [Eyer, 2004].

Furthermore, the two following simplifications might be crucial for the modeling results: First, the length of the reduction in NADW formation during Heinrich event 1 and YD might be too long. It is known that the climate system might need more than 500 yr to regain initial temperatures after the end of a freshwater pulse mimicking the processes of a Heinrich event [e.g. Marchal et al., 1998a; Clark et al., 2002; Knutti et al., 2004]. Thus, the NADW formation might resume earlier at the end of the cold events than the temperature maxima in the North. Second, the low pass filtering of the ice core temperature proxies especially in the North reduces the abruptness of the Northern Hemisphere temperature fluctuations, e.g. stretching the warming at the end of the YD from less than a century to nearly half a millennium. The simulated response of both $p \mathrm{CO}_{2}$ outgassing through ocean warming and changes in terrestrial carbon storage are therefore delayed. Both these processes would inflict on the carbon cycle by an earlier rise in $p \mathrm{CO}_{2}$ and would therefore reduce the still existing offsets between simulation results and data sets (Fig. 12).

\subsection{The weak link - enhancing the biological pump}

As reviewed in section 5.3, there is evidence for enhanced glacial export production in the Southern Ocean (south of $40^{\circ} \mathrm{S}$ ) through iron fertilization, although it is still a matter of debate. This enhancement of the biological pump was assumed here as this process would - beside its downdraw of $p \mathrm{CO}_{2}$ - reduce atmospheric $\delta^{13} \mathrm{C}$ precisely at the right time during the onset of the rise in $p \mathrm{CO}_{2}$ at $18 \mathrm{kyr} \mathrm{BP}$. Given the uncertainties in the Taylor Dome $\delta^{13} \mathrm{C}$ records discussed earlier, the question arises which alternative scenarios are possible and whether there is other evidence for an enhanced glacial export. Some recent studies set upper limits to the impact of an enhancement of Southern Ocean export production through Fe fertilization. Röthlisberger et al. [2004] conclude an upper limit of 20 ppmv from an Antarctic ice core perspective. They compare reductions in the aeolian dust content during Termination I and the Antarctic warming events between 60 and $30 \mathrm{kyr} \mathrm{BP}$, which parallel atmospheric $p \mathrm{CO}_{2}$ peaks of up to $20 \mathrm{ppmv}$. However, biological or physical processes of iron utilization and uptake are not considered any further. The modeling study of Bopp et al. [2003] sets an upper limits of the $p \mathrm{CO}_{2}$ increase mediated through iron to $30 \mathrm{ppmv}$, but a variety of model based scenarios span the range of 5-45 ppmv [see review by Ridgwell, 2003b]. In a recent review on the role of marine biology on $\mathrm{G} / \mathrm{IG} p \mathrm{CO}_{2}$ it was stated that iron fertilization and associated mechanisms can be responsible for no more than half of the observed variations [Kohfeld et al., 2005]. The reassessment of $\mathrm{N}$-isotopes [Robinson et al., 2004] restricts the enhancement of Southern Ocean productivity further and the question arises whether there are alternative scenarios to be considered.

One attractive alternative scenario is the silicic acid leakage hypothesis [Brzezinski et al., 2002; Matsumoto et al., 2002] which is also based on Fe fertilization as initial trigger and would thus have a similar temporal evolution as our initial Fe fertilization approach. Briefly, this hypothesis assumes that the Fe fertilization in the Southern Ocean initiates a reduced Si:N uptake ratio in diatoms there. This leads to a northward propagation of un-utilized silicic acid. In mid to low latitudes modifications in nutrient concentrations shift phytoplankton community assemblages towards diatoms, which then can increase their export production there. The down-draw of $p \mathrm{CO}_{2}$ through higher organic matter fluxes would be accompanied by local changes in the rain ratio (a weaker carbonate pump) which would additionally reduce $p \mathrm{CO}_{2}$. Unfortunately, in our present model setup we are unable to test this scenario as glacial macro nutrient concentrations in the equatorial surface ocean boxes do not allow any further enhancement in marine export production. We have to acknowledge, that our preindustrial biological productivity in low latitudes is already $30 \%$ smaller than deduced from data-based inverse modeling studies [Schlitzer, 2000]. Therefore, our modeling restriction can not falsify the silicic acid leakage hypothesis.

As further alternative the enhancement of marine glacial export production in the North Pacific, another HNLC region, might be a process of interest. The upper limit of its impact was estimated to 9 ppmv [Röthlisberger et al., 2004].

In summary, we believe that the marine biology plays a role in the quest of explaining the observed G/IG rise in $p \mathrm{CO}_{2}$. Its magnitude seems to be on the order of $20 \mathrm{ppmv}$, but details need to be clarified by further studies.

\subsection{Evidence from paleoceanographic $\delta^{13} \mathrm{C}$ data}

What data evidence is there for the reliability of our ocean setting during the LGM as summarized in Table 3? To challenge our results with paleo data we compare the evolution of oceanic $\delta^{13} \mathrm{C}$ across Termination I in our model with $\delta^{13} \mathrm{C}$ of benthic foraminifera (Fig. 13).

Depending on the selection of sediment cores, the $\delta^{13} \mathrm{C}$ signal recorded in benthic foraminifera increased from LGM to preindustrial times by $0.30-0.46 \%$ [Curry et al., 1988; 
Duplessy et al., 1988]. The rise is largest $(0.8 \% 0)$ in the deep Southern Ocean [Curry et al., 1988; Curry and Oppo, 2005] with maximum differences $(1.4 \%$ ) in waters below $2500 \mathrm{~m}$ [Hodell et al., 2003]. The Indo-Pacific and the Atlantic Ocean exhibit significant smaller amplitudes of 0.40.5\% [Curry et al., 1988; Boyle, 1992], while the $\delta^{13} \mathrm{C}$ rise also varies with depth. Particularly, in the Atlantic, $\delta^{13} \mathrm{C}$ shifts from a G/IG drop in waters above $2000 \mathrm{~m}$ to a rise in waters below [Boyle, 1992; Oppo and Lehman, 1993; Curry and Oppo, 2005].

We simulate a mean rise in oceanic $\delta^{13} \mathrm{C}$ of $0.36 \%$ from LGM to preindustrial times (Tables 1, 3). Further, our simulations reveal a $\mathrm{G} / \mathrm{IG}$ rise in $\delta^{13} \mathrm{C}$ in the deep Atlantic, Southern Ocean, and Indo-Pacific of $-0.15 \%, 1.07 \%$, and $0.54 \%$, respectively (Tables 1, 3). While the rise in the Southern Ocean and Indo-Pacific are at the upper range of reconstructions, the drop in the Atlantic Ocean is only found in the upper $2 \mathrm{~km}$ of the water column. This could indicate that either ocean circulation pattern in the Atlantic changed differently than assumed here or that marine export production was increased during glacial times in equatorial regions as suggested by the "silicic acid leakage hypothesis" [Brzezinski et al., 2002; Matsumoto et al., 2002].

Nevertheless, across Termination I, our simulation of deep ocean $\delta^{13} \mathrm{C}$ covers the temporal evolution of selected records of $\delta^{13} \mathrm{C}$ in benthic foraminifera rather well (Fig. 13). The amplitude is slightly larger in the simulation than in the IndoPacific data, and offset by $0.5 \%$ to more positive values in the Southern Ocean. In the Atlantic the simulated amplitude is slightly smaller than in the data, but our simulation seems to cover millennial-scale variations on the order of $0.5 \%$ across the transition. Furthermore, our simulations show a distinct negative peak in $\delta^{13} \mathrm{C}$ of $1-2 \%$ in equatorial surface and intermediate waters, parallel with a peak of $0.3 \%$ in the North Atlantic, probably caused by the shutdown of the NADW formation during Heinrich event 1 . The simulation predict a decline in $\delta^{13} \mathrm{C}$ of $0.2 \%$ in the Southern Ocean and rather stable $\delta^{13} \mathrm{C}$ values in the surface waters of the Indo-Pacific (a slight increase of $+0.2 \%$ in the equatorial regions, and a slight decrease of $-0.1 \%$ in the North).

The simulated negative excursion in intermediate Atlantic waters is significant and should therefore be traceable in sediment records. There is some evidence for a decline of $0.5-$ $1.0 \%$ in $\delta^{13} \mathrm{C}$ from a selection of cores of intermediate depth (400-1500 m) from the Bahamas [Slowey and Curry, 1995]. However, as age models in this study were developed only for two out of nine cores it is difficult to interprete if the minima in $\delta^{13} \mathrm{C}$ seen in these cores occurred during the transition or later on in the early Holocene. We refrain from a comparison of modeled surface water $\delta^{13} \mathrm{C}$ with data derived from planktic foraminifera as planktic $\delta^{13} \mathrm{C}$ can be heavily overprinted by various effects (disequilibrium, dissolution, habitat, carbonate ion effect) [Spero et al., 1997; Mulitza et al., 1999]. Therefore, the interpretation of surface $\delta^{13} \mathrm{C}$ data is limited and might need further work in order to understand underlying processes affecting stable carbon isotope fractionation in planktic foraminifera.

We emphasize that the $\delta^{13} \mathrm{C}$ model-data comparison gives some insights into model performance but provides only a restricted evaluation of the entire model outcome. Compilations of freely available data sets were chosen here as representative for certain ocean basins. However, this particular choice does not necessarily represent the actual average basin- $\delta^{13} \mathrm{C}$ values across the transition - and therefore the optimal validation target for the average $\delta^{13} \mathrm{C}$ values of our ocean model boxes

\subsection{Robustness of our results}

In the light of the uncertainties of our approach discussed above the question arises how robust our final G/IG scenarios are. While the timing and magnitude of several processes are well documented, others still allow a range of possible implementations. Below we discuss the robustness of all major processes summarized in Table 2. In doing so we focus on their reliability and give an estimate on their credibility in our present carbon cycle model and in comparison with other modeling results.

Sea level rise (highly credible): In the context of our study the resolution of sea level reconstruction and its timing based on coral records [Fairbanks, 1990] is sufficient. Other studies report results of the same order of magnitude as ours, e.g. a reduction of $p \mathrm{CO}_{2}$ during Termination I by $7 \mathrm{ppmv}$ [Matsumoto et al., 2002].

Ocean temperatures (credible) and sea ice (fairly credible, but model dependent): Multi-proxy approaches seemed to be the best estimates to derive reliable temperature proxies. There might be improvements through new sediment cores and better methodologies, but in the coarse resolution of our model this might alter our $p \mathrm{CO}_{2}$ estimates only very little. The time-slice reconstruction of sea ice coverage is still improving for the LGM [e.g. Gersonde et al., 2005]. Again, the limitations of our model design restrict any fundamental changes through an updated sea ice coverage. But it has to be kept in mind (as discussed earlier) that the impact of sea ice and thus gas-exchange on $p \mathrm{CO}_{2}$ is strongly model dependent [Archer et al., 2003].

Ocean circulation (fairly credible): Our knowledge on changes in NADW formation were improved greatly in the past years. Especially the possibility to fix the resumptions of the NADW in time is of importance in this context. The magnitude of the NADW formation might in detail still be a matter of debate (e.g. in the Younger Dryas), but the general picture, which emerges so far seems to be stable. The circulation in the Indo-Pacific was kept constant in our scenarios which is supported by $\delta^{13} \mathrm{C}$ [Mix et al., 1991] and $\Delta^{14} \mathrm{C}$ [Broecker et al., 2004] data, suggesting that the glacial ventilation of the deep Pacific Ocean was not much different from today's situation. However, it has to be stressed that the understanding of ocean circulation strength is still limited. Circulation patterns calculated from full OGCMs for the present day situation vary still considerably from each other and from observations, as shown in the Ocean Carboncycle model Inter-comparison Project OCMIP [e.g. Doney et al., 2004].

Shallow water carbonate production (fairly credible): The data constraints limit the impact of coral reef growth on $p \mathrm{CO}_{2}$ during Termination I [Vecsei and Berger, 2004] espe- 
cially via the time domain as their contribution is tightly coupled to sea level rise above $70 \mathrm{~m}$ below present. We therefore argue that the coral reef hypothesis as the dominant process explaining the $\mathrm{G} / \mathrm{IG}$ rise in $p \mathrm{CO}_{2}$ is rather unlikely. However, the magnitude of the $p \mathrm{CO}_{2}$ rise caused by shallow water contributions (so far 1-3 ppmv) might increase slightly through carbonate accumulation besides that of coral reefs, e.g through accumulation on isolated banks [Vecsei, 2004].

Terrestrial biosphere (fairly credible): Data and models nowadays agree that the carbon storage on land increased during Termination I, its magnitude, however, is still a matter of debate. We estimate that the overall rise in terrestrial carbon as well as the large perturbation during the YD cold interval imprint an uncertainty of about 10 ppmv onto our results. This is based on intercomparsions of DGVMs [Cramer et al., 2001] and the sensitivity of individual models to different climate forcings, as seen from studies mimicking a NADW shutdown and its consequent cooling of the Northern Hemisphere [Scholze et al., 2003; Köhler et al., 2005].

Southern Ocean vertical mixing (fairly credible): There is evidence for decreased glacial Southern Ocean water column stratification from various records, different proxies and the support by modeling studies [e.g. François et al., 1997; Crosta and Shemesh, 2002; Hodell et al., 2003; Gildor et al., 2002; Paillard and Parrenin, 2004]. But here, our results demand an abrupt increase in vertical mixing rates at the onset of the $p \mathrm{CO}_{2}$ rise to reconstruct especially the evolution of the atmospheric $\delta^{13} \mathrm{C}$ record. Robust evidence from proxy reconstructions on the timing and the velocity of the changes are hard to find. Therefore, our assumption of the rapid increase in mixing can be understood as a result of our study, which asks for verification from more complex physical ocean models or new paleoceanographic data sets. As this process explains the largest part of the $\mathrm{G} / \mathrm{IG}$ rise in $p \mathrm{CO}_{2}$ and most of the $0.5 \%$ drop in $\delta^{13} \mathrm{C}$ at $17 \mathrm{kyr} \mathrm{BP}$, large changes here would significantly impact our modeling results. Again, it has to be said that different models might come up with different results [Archer et al., 2003]. Therefore, the question is not only what support our approach has from paleo data sets, but also what the model-dependent answer to it might be.

Sediment/ocean exchange fluxes (fairly credible): The global pattern of changes in the lysocline are fairly well known. However, all paleo-reconstructions of carbonate production so far are based on the large shell-size fraction $(>63 \mu \mathrm{m})$ neglecting any impact of smaller individuals. The calculation of the carbonate saturation depth with our box model is also a rough estimate, as temperature and salinity (which together with pressure determine the saturation depth) do vary with depth in nature, but were kept constant below $1000 \mathrm{~m}$ in our model. Minor improvements can be expected if not only net changes in the DIC and ALK inventories were modeled, but the riverine input of weathering products would be accounted for separately. These improvements would only modify details of the overall behavior of the carbonate cycle. Further improvement can also be expected from process-based modeling of sediment diagenesis. We nevertheless believe that the global scale impacts of sedimentation/dissolution are captured fairly well in our approach.
Biological pump (uncertain): As outlined in the previous section, the detailed response of the marine biology is not well constrained. Data point to a constant rain ratio which tightly connects the soft-tissue and the carbonate pump. Iron fertilization seems to be a tempting hypothesis explaining up to $20 \mathrm{ppmv}$ of the $p \mathrm{CO}_{2}$ rise. However, so far one can only speculate about the details of shifts in community structure or enhanced glacial export production. It would be on the other hand very surprising if major physical and biogeochemical parameters changed, but the export production of the marine biology stayed constant over time.

In summary, our approach was based on the implementation of highly credible processes first. The more uncertain processes were added later on. We like to emphasize that we did not fine-tune uncertain processes such as the impact of the biological pump to accurately match the ice core observations. We are aware of its limited reliability and therefore ask for other studies detailing single parts of the carbon cycle to disentangle still open questions.

\section{Conclusions}

The processes causing relevant changes on $p \mathrm{CO}_{2}$ as summarized in Table 2 are all important during the last termination and in line with the temporal development of the atmospheric carbon records (Fig. 12). They are in decreasing order of their impact on $p \mathrm{CO}_{2}$ : The rise in Southern Ocean vertical mixing rates $(>30 \mathrm{ppmv})$, decreases in alkalinity and carbon inventories ( $>30 \mathrm{ppmv}$ ), the reduction of the biological pump $(\sim 20 \mathrm{ppmv})$, the rise in ocean temperatures $(15-20 \mathrm{ppmv})$, the resumption of ocean circulation $(15-20 \mathrm{ppmv})$, and coral reef growth $(<5 \mathrm{ppmv})$. The regrowth of the terrestrial biosphere, sea level rise and the increase in gas exchange through reduced sea ice cover operate in the opposite direction, decreasing $p \mathrm{CO}_{2}$ during Termination I by $\sim 30$ ppmv. While the dynamic of the physical system seems to be constrained rather well by proxy data, changes in biogeochemical processes are more uncertain. All the major processes contributing to the $\mathrm{G} / \mathrm{IG} p \mathrm{CO}_{2}$ change seem to be identified, although the size of their contributions may have to be revised. Nevertheless, disentangling different processes over the course of the transition as done here is the only way to gain insights into causes of temporal changes in the data records. For example, a study based on steady state simulations for the LGM and preindustrial times undertaken with an Earth system model of intermediate complexity concludes that the initial drop in $\delta^{13} \mathrm{C}$ might have been caused by an enhanced marine biological pump during the LGM [Brovkin et al., 2002]. We argue that a complete picture of $\mathrm{G} / \mathrm{IG}$ change only emerges if all subsequent temporal variations in both atmospheric carbon records can be addressed. Therefore, the conclusions of Brovkin et al. [2002] may have to be revised based on the importance of Southern Ocean stratification breakdown at the onset of the termination as proposed here.

According to our model assumptions which are bound as closely as possible to data constraints we are able to reproduce the temporal evolution of the atmospheric carbon 
records during Termination I. While this approach does not exclude other scenarios, we emphasize that alternatives scenarios also need to be able to reproduce the time-dependent development of as much variables of the carbon cycle as possible. A plausible scenario of the sequence of events during the last deglaciation according to this study is the following: A (18 kyr BP): A reduction in aeolian Fe input into the Southern Ocean results in lower marine export production to the deep ocean and an outgassing of $\mathrm{CO}_{2}$. B (17 kyr BP): Parallel to Southern Hemisphere warming, Southern Ocean winter sea ice cover is largely reduced and leads to the breakdown of Southern Ocean stratification. C (15 kyr BP): The reduced Southern Ocean sea ice opens water transport ways into the Atlantic Ocean and acts - after the shutdown of NADW formation during Heinrich event 1 - as a flywheel on the THC. With a delay of about $1.5-2 \mathrm{kyr}$ NADW formation resumes with at least intermediate strength. D $(15-12 \mathrm{kyr} B P)$ : In addition to a further strengthening of the THC after the YD - during which the strength of the NADW formation is only slightly reduced - the most relevant changes to $p \mathrm{CO}_{2}$ and $\delta^{13} \mathrm{C}$ during the $\mathrm{BA}$ and the $\mathrm{YD}$ are $\mathrm{CO}_{2}$ fertilization and Northern hemispherical temperature changes modifying the carbon storage in the terrestrial biosphere. E (after $14 \mathrm{kyr}$ $\mathrm{BP})$ : Coral reef growth with a subsequent outgassing of $\mathrm{CO}_{2}$ starts only after MWP $1 \mathrm{~A}$ and initially only at a marginal rate.

Acknowledgements. Data sets were kindly provided by K. Hughen, R. Thunell, T. Bickert, and E. Boyle. K. Wirtz helped us in digitalizing ${ }^{14} \mathrm{C}$ production rates. $\mathrm{K}$. Matsumoto pointed us to the denitrifi cation pathway. This work greatly benefi ted from discussions with and comments from J. Bijma, G. Knorr, G.J. Reichart, M. Schartau, M. Siddall, C. Völker, D.A. Wolf-Gladrow. The manuscript improved greatly through the thoughtful comments of two anonymous reviewers. This work is part of the project RESPIC funded by the German Ministry of Education and Research (BMBF) within the German climate research program DEKLIM.

\section{References}

Adams, J. M., and H. Faure (1998), A new estimate of changing carbon storage on land since the Last Glacial Maximum, based on global land ecosystem reconstruction, Global and Planetary Change, 16-17, 3-24.

Adkins, J. F., K. McIntyre, and D. P. Schrag (2002), The salinity, temperature, and $\delta^{18} \mathrm{O}$ of the glacial deep ocean, Science, 298, 1769-1773.

Aeschbach-Hertig, W., F. Peeters, U. Beyerle, and R. Kipfer (2000), Palaeotemperature reconstruction from noble gases in ground water taking into account equilibration with entrapped air, $\mathrm{Na}$ ture, 405, 1040-1044.

Alley, R. B., and P. U. Clark (1999), The deglaciation of the northern hemisphere: a global perspective, Annual Reviews in Earth and Planetary Sciences, 27, 149-182.

Amiotte-Suchet, P., J.-L. Probst, and W. Ludwig (2003), Worldwide distribution of continental rock lithology: implications for the atmospheric/soil $\mathrm{CO}_{2}$ uptake by continental weathering and alkalinity river transport to the oceans, Global Biogeochemical Cycles, 17, 1038, doi: 10.1029/GB2002GB001,891.

Anderson, R. F., N. Kumar, R. A. Mortlock, P. N. Froelich, P. K. an B. Dittrich-Hannen, and M. Suter (1998), Late-Quaternary changes in productivity of the Southern Ocean, Journal of Marine Systems, 17, 497-514.

Anderson, R. F., Z. Chase, M. Q. Fleisher, and J. Sachs (2002), The Southern Oceans's biological pump during the Last Glacial Maximum, Deep-Sea Research II, 49, 1909-1938.

Archer, D. (1991), Modelling the calcite lysocline, Journal of Geophysical Research, 96(C9), 17,037-17,050.

Archer, D., and E. Maier-Reimer (1994), Effect of deep-sea sedimentary calcite preservation on atmospheric $\mathrm{CO}_{2}$ concentration, Nature, 367, 260-263.

Archer, D., H. Kheshgi, and E. Maier-Reimer (1998), Dynamics of fossil fuel neutralization by marine $\mathrm{CaCO}_{3}$, Global Biogeochemical Cycles, 12, 259-276.

Archer, D., A. Winguth, D. Lea, and N. Mahowald (2000a), What caused the glacial/interglacial atmospheric $p \mathrm{CO}_{2}$ cycles?, Reviews of Geophysics, 38(2), 159-189.

Archer, D. E., G. Eshel, A. Winguth, W. Broecker, R. Pierrehumbert, M. Tobis, and R. Jacob (2000b), Atmospheric $p \mathrm{CO}_{2}$ sensitivity to the biological pump in the ocean, Global Biogeochemical Cycles, 14(4), 1219-1230.

Archer, D. E., P. A. Martin, J. Milovich, V. Brovkin, G.-K. Plattner, and C. Ashendel (2003), Model sensitivity in the effect of Antarctic sea ice and stratifi cation on atmospheric $p \mathrm{CO}_{2}$, Paleoceanography, 18, 1012, doi: 10.1029/2002PA000,760.

Barnola, J. M., D. Raynaud, Y. S. Korotkevich, and C. Lorius (1987), Vostok ice core provides 160,000-year record of atmospheric $\mathrm{CO}_{2}$, Nature, 329, 408-414.

Beck, J. W., D. A. Richards, R. L. Edwards, B. W. Silverman, P. L. Smart, D. J. Donahue, S. Hererra-Osterheld, G. S. Burr, L. Calsoyas, A. J. T. Jull, and D. Biddulph (2001), Extremely large variations of atmospheric ${ }^{14} \mathrm{C}$ concentration during the Last Glacial Period, Science, 292, 2453-2458.

Becquey, S., and R. Gersonde (2003), A 0.55-Ma paleotemperature record from the subantarctic zone: implications for the Antarctic Circumpolar Current development, Paleoceanography, 18, 1014, doi: 10.1029/2000PA000,576.

Berger, W. H. (1968), Planktonic foraminifera: selective solution and paleoclimatic interpretation, Deep-Sea Research, 15, 31-43.

Berger, W. H. (1982), Increase of carbon dioxide in the atmosphere during deglaciation: the coral reef hypothesis, Naturwissenschaften, 69, 87-88.

Berger, W. H., and R. S. Keir (1984), Glacial-Holocene changes in atmospheric $\mathrm{CO}_{2}$ and the deep-sea record, in Climate processes and climate sensitivity, Geophysical Monograph, vol. 29, edited by J. E. Hansen and T. Takahashi, pp. 337-351, American Geophysical Union, Washington, D.C., USA.

Bopp, L., K. E. Kohfeld, and C. L. Quere (2003), Dust impact on marine biota and atmospheric $\mathrm{CO}_{2}$ during glacial periods, Paleoceanography, 18, 1046, doi: 10.1029/2002PA000,810.

Boyle, E. A. (1992), Cadmium and $\delta^{13} \mathrm{C}$ paleochemical ocean distributions during the stage 2 glacial maximum, Annual Reviews in Earth and Planetary Sciences, 20, 245-287.

Broecker, W., J. Lynch-Stieglitz, D. Archer, M. Hofmann, E. MaierReimer, O. Marchal, T. Stocker, and N. Gruber (1999), How strong is the Harvardton-Bear constraint?, Global Biogeochemical Cycles, 13(4), 817-820.

Broecker, W., S. Barker, E. Clark, I. Hajdas, G. Bonani, and L. Stott (2004), Ventilation of the glacial deep Pacific Ocean, Science, 306, 1169-1172.

Broecker, W. S., and G. M. Henderson (1998), The sequence of events surrounding Termination II and their implications for the cause of glacial-interglacial $\mathrm{CO}_{2}$ changes, Paleoceanography, 13(4), 352-364.

Broecker, W. S., and T.-H. Peng (1986), Carbon Cycle 1985: 
Glacial to interglacial changes in the operation of the global carbon cycle, Radiocarbon, 28, 309-327.

Broecker, W. S., and T.-H. Peng (1987), The role of $\mathrm{CaCO}_{3}$ compensation in the glacial to interglacial atmospheric $\mathrm{CO}_{2}$ change, Global Biogeochemical Cycles, 1, 15-29.

Broecker, W. S., and T. Takahashi (1978), The relationship between lysocline depth and in situ carbonate ion concentration, DeepSea Research, 25, 65-95.

Brook, E. J., T. Sowers, and J. Orchardo (1996), Rapid variations in atmospheric methane concentration during the past 110,000 years, Science, 273, 1087-1091.

Brovkin, V., M. Hofmann, J. Bendtsen, and A. Ganopolski (2002), Ocean biology could control atmospheric $\delta^{13} \mathrm{C}$ during glacialinterglacial cycle, Geochemistry, Geophysics, Geosystems, 3, 1027, doi: 10.1029/2001GC000,270.

Brzezinski, M. A., C. J. Pride, V. M. Franck, D. M. Sigman, J. L. S. K. Matsumoto, N. Gruber, G. H. Rau, and K. H. Coale (2002), A switch from $\mathrm{Si}(\mathrm{OH})_{4}$ to $\mathrm{NO}_{3}^{-}$depletion in the glacial Southern Ocean, Geophysical Research Letters, 29, doi: 10.1029/2001GL14,349.

Cavalieri, D. J., P. Gloersen, C. L. .Parkinson, J. C. Comiso, and H. J. Zwally (1997), Observed hemispheric asymmetry in global sea ice changes, Science, 278, 1104-1106.

Charles, C. D., and R. G. Fairbanks (1990), Glacial to interglacial changes in the isotopic gradients of Southern Ocean surface water, in Geological history of the polar oceans: Artic versus Antarctic, edited by U. Bleil and J. Thiede, pp. 519-538, Kluwer, Dordrecht, The Netherlands.

Charles, C. D., and R. G. Fairbanks (1992), Evidence from Southern Ocean sediments for the effect of North Atlantic deep-water flux on climate, Nature, 355, 416-419.

Chase, Z., R. F. Anderson, M. Q. Fleisher, and P. W. Kubik (2003), Accumulation of biogenic and lithogenic material in the Pacifi $\mathrm{c}$ sector of the Southern Ocean during the past 40,000 years, DeepSea Research II, 50, 799-832.

Clark, P. U., N. G. Pisias, T. F. Stocker, and A. J. Weaver (2002), The role of the thermohaline circulation in abrupt climate change, Nature, 415, 863-869.

CLIMAP (1976), The surface of the ice-age Earth, Science, 191, $1131-1137$.

Conkright, M., S. Levitus, and T. Boyer (1994), World Ocean Atlas Volume 1: Nutrients, NOAA Atlas NESDIS 1, U.S. Department of Commerce, Washington, D.C.

Cramer, W., A. Bondeau, F. I. Woodward, I. C. Prentice, R. A. Betts, V. Brovkin, P. M. Cox, V. Fisher, J. A. Foley, A. D. Friend, C. Kucharik, M. R. Lomas, N. Ramankutty, S. Sitch, B. Smith, A. White, and C. Young-Molling (2001), Global response of terrestrial ecosystem structure and function to $\mathrm{CO}_{2}$ and climate change: results from six dynamic global vegetation models, Global Change Biology, 7, 357-375.

Crosta, X., and A. Shemesh (2002), Reconciling down core anticorrelation of diatom carbon and nitrogen isotopic ratios from the Southern Ocean, Paleoceanography, 17, 1010, doi: 10.1029/2000PA000,565.

Crosta, X., J.-J. Pichon, and L. H. Burckle (1998a), Application of modern analog technique to marine Antarctic diatoms: Reconstruction of maximum sea-ice extent at the Last Glacial Maximum, Paleoceanography, 13, 284-297.

Crosta, X., J.-J. Pichon, and L. H. Burckle (1998b), Rearaisal of Antarctic seasonal sea-ice extent at the Last Glacial Maximum, Geophysical Research Letters, 14, 2703-2706.

Crowley, T. J. (1983), Calcium-carbonate preservation patterns in the central North Atlantic during the last 150,000 years, Marine Geology, 51, 1-14.
Curry, W. B., and G. P. Lohmann (1986), Late Quaternary carbonate sedimentation at the Sierra Leone rise (eastern equatorial Atlantic Ocean), Marine Geology, 70, 223-250.

Curry, W. B., and D. W. Oppo (2005), Glacial water mass geometry and the distribution of $\delta^{13} \mathrm{C}$ of $\sum \mathrm{CO}_{2}$ in the western Atlantic Ocean, Paleoceanography, 20, PA1017, doi: 10.1029/2004PA001,021.

Curry, W. B., J. C. Duplessy, L. D. Labeyrie, and N. J. Shackleton (1988), Changes in the distribution of $\delta^{13} \mathrm{C}$ of deep water $\sum \mathrm{CO}_{2}$ between the last glaciation and the Holocene, Paleoceanography, 3(3), 317-341.

Delaygue, G., T. Stocker, F. Joos, and G.-K. Plattner (2003), Simulation of atmospheric radiocarbon during abrupt oceanic circulation changes: trying to reconcile models and reconstructions, Quaternary Science Reviews, 22, 1647-1658.

Doney, S. C., K. Lindsay, K. Caldeira, J.-M. Campin, H. Drange, J.-C. Dutay, M. Follows, Y. Gao, A. Gnanadesikan, N. Gruber, A. Ishida, F. Joos, G. Madec, E. Maier-Reimer, J. C. Marshall, R. J. Matear, P. Monfray, A. Mouchet, R. Najjar, J. C. Orr, G.-K. Plattner, J. Sarmiento, R. Schlitzer, R. Slater, I. J. Totterdell, M.-F. Weirig, Y. Yamanaka, and A. Yool (2004), Evaluating global ocean carbon models: the importance of realistic physics, Global Biogeochemical Cycles, 18, GB3017, doi: 10.1029/2003GB002,150.

Duplessy, J. C., N. J. Shackleton, R. G. Fairbanks, L. Labeyrie, D. Oppo, and N. Kallel (1988), Deep water source variations during the last climatic cycle and their impact on the global deepwater circulation, Paleoceanography, 3, 343-360.

Emanuel, W. R., G. G. Killough, W. M. Post, and H. H. Shugart (1984), Modeling terrestrial ecosystems in the global carbon cycle with shifts in carbon storage capacity by land-use change, Ecology, 65, 970-983.

Eyer, M. (2004), Highly resolved $\delta^{13} \mathrm{C}$ measurements on $\mathrm{CO}_{2}$ in air from Antarctic ice cores, Ph.D. thesis, University of Bern, Bern, Switzerland.

Fairbanks, R. G. (1990), The age and origin of the Younger Dryas climate event in Greenland ice cores, Paleoceanography, 5, 937 948.

Farrell, J. W., and W. L. Prell (1989), Climate change and $\mathrm{CaCO}_{3}$ preservation: An 800,000 year bathymetric reconstruction from the central equatorial Pacifi c Ocean, Paleoceanography, 4, 447466.

Fichefet, T., B. Tartinville, and H. Goosse (2003), Antarctic sea ice variability during 1958-1999: a simulation with a global iceocean model, Journal of Geophysical Research, 108(C3), 3102, doi: 10.1029/2001JC001,148.

Fischer, H., M. Wahlen, J. Smith, D. Mastroianni, and B. Deck (1999), Ice core records of atmospheric $\mathrm{CO}_{2}$ around the last three glacial terminations, Science, 283, 1712-1714.

François, R., M. A. Altabet, E.-F. Yu, D. M. Sigman, M. P. Pacon, M. Frankl, G. Bohrmann, G. Bareille, and L. D. Labeyrie (1997), Contribution of Southern Ocean surface-water stratifi cation to low atmopsheric $\mathrm{CO}_{2}$ concentrations during the last glacial period, Nature, 389, 929-935.

Frank, M., R. Gersonde, M. R. van der Loeff, G. B. C. C. Nürnberg, P. M. Kubik, M. Suter, and A. Mangini (2000), Similar glacial and interglacial export bioproductivity in the Atlantic sector of the Southern Ocean: Multiproxy evidence and implications for glacial atmospheric $\mathrm{CO}_{2}$, Paleoceanography, 15, 642-658.

Ganachaud, A., and C. Wunsch (2000), Improved estimates of global ocean circulation, heat transport and mixing from hydrographic data, Nature, 408, 453-457.

Gersonde, R., X. Crosta, A. Abelmann, and L. Armand (2005), Sea-surface temperature and sea ice distribution of the South- 
ern Ocean at the EPILOG Last Glacial Maximum - a circumAntarctic view based on siliceous microfossil records, Quaternary Science Reviews, 24, 869-896.

Gildor, H., E. Tziperman, and J. R. Toggweiler (2002), Sea ice switch mechanism and glacial-interglacial $\mathrm{CO}_{2}$ variations, Global Biogeochemical Cycles, 16, 10.1029/2001GB001,446.

Gnanadesikan, A., R. D. Slater, N. Gruber, and J. L. Sarmiento (2002), Oceanic vertical exchange and new production: a comparison between models and observations, Deep-Sea Research II, 49, 363-401.

Grootes, P. M., and M. Stuiver (1997), Oxygen 18/16 variability in Greenland snow and ice with $10^{3}$ to $10^{5}$-year time resolution, Journal of Geophysical Research, 102, 26,455-26,470.

Guilderson, T. P., R. G. Fairbanks, and J. L. Rubenstone (2001), Tropical Atlantic coral oxygen isotopes: glacial-interglacial sea surface temperature and climate change, Marine Geology, 172, 75-89.

Harvey, L. D. D. (2001), A quasi-one-dimensional coupled climatecarbon cycle model. 2 . The carbon cycle component, Journal of Geophysical Research, 106(C10), 22,355-22,372.

Heimann, M., and E. Maier-Reimer (1996), On the relations between the oceanic uptake of $\mathrm{CO}_{2}$ and its carbon isotops, Global Biogeochemical Cycles, 10, 89-110.

Heimann, M., and P. Monfray (1989), Spatial and Temporal Variation of the Gas Exchange Coefficient for $\mathrm{CO}_{2}:$ 1. Data Analysis and Global Validation, Reports, vol. 31, Max Planck Institute for Meteorology, Hamburg, Germany.

Heinze, C., E. Maier-Reimer, and K. Winn (1991), Glacial $p \mathrm{CO}_{2}$ reduction by the world ocean: experiments with the Hamburg Carbon Cycle Model, Paleoceanography, 6(4), 395-430.

Hemming, S. R. (2004), Heinrich events: massive late Pleistocene detritus layers of the North Atlantic and their global climate imprint, Reviews of Geophysics, 42, RG1005, doi: 10.1029/2003RG000,128.

Hodell, D. A. (2002), Ms 177SR-120, Chapter 9, Table T2, in Proceedings of the Ocean Drilling Program, Scientific Results Vol 177 [Online], edited by R. Gersonde, D. A. Hodell, and P. Blum, http://wwwodp.tamu.edu/publications/177_SR/synth/synth.htm.

Hodell, D. A., K. A. Venz, C. D. Charles, and U. S. Ninnemann (2003), Pleistocene vertical carbon isotope and carbonate gradients in the South Atlantic sector of the Southern Ocean, Geochemistry, Geophysics, Geosystems, 4, 1004, doi: 10.1029/2002GC000,367.

Howard, W. R., and W. L. Prell (1994), Late Quaternary $\mathrm{CaCO}_{3}$ production and preservation in the Southern Ocean: Implications for oceanic and atmospheric carbon cycling, Paleoceanography, 9, 453-482.

Hughen, K., S. Lehman, J. Southon, J. Overpeck, O. Marchal, C. Herring, and J. Turnbull (2004), ${ }^{14} \mathrm{C}$ activity and global carbon cycle changes over the past 50,000 years, Science, 303, 202207.

Ito, T., J. Marshall, and M. Follows (2004), What controls the uptake of transient tracers in the Southern Ocean?, Global Biogeochemical Cycles, 18, GB2021, doi: 10.1029/2003GB002,103.

Joos, F., S. Gerber, I. C. Prentice, B. L. Otto-Bliesner, and P. J. Valdes (2004), Transient simulations of Holocenic atmospheric carbon dioxide and terrestrial carbon since the Last Glacial Maximum, Global Biogeochemical Cycles, 18, GB2002, doi: 10.1029/2003GB002,156.

Jouzel, J., V. Masson, O. Cattani, S. Falourd, M. Stievenard, B. Stenni, A. Longinelli, S. J. Johnsen, J. P. Steffenssen, J. R. Petit, J. Schwander, R. Souchez, and N. I. Barkov (2001), A new 27 ky high resolution East Antarctic climate record, Geophysical
Research Letters, 28, 3199-3202.

Kageyama, M., O. Peyron, S. Pinot, P. Tarasov, J. Guiot, S. Jousaume, and G. Ramstein (2001), The Last Glacial Maximum climate over Europe and western Siberia: a PMIP comparsion between models and data, Climate Dynamics, 17, 23-43.

Kaplan, J. O., I. C. Prentice, W. Knorr, and P. J. Valdes (2002), Modeling the dynamics of terrestrial carbon storage since the Last Glacial Maximum, Geophysical Research Letters, 29, 2074, doi: 10.1029/2002GL015,230.

Keir (1988), On the late Pleistocene ocean geochemistry and circulation, Paleoceanography, 3, 413-445.

Key, R. M., A. Kozyr, C. L. Sabine, K. Lee, R. Wanninkhof, J. L. Bullister, R. A. Feely, F. J. Millero, C. Mordy, and T.-H. Peng (2004), A global ocean carbon climatology: results from global data analysis project (GLODAP), Global Biogeochemical Cycles, 18, GB4031, doi: 10.1029/2004GB002,247.

Kim, S.-J., G. M. Flato, G. J. Boer, and N. A. McFarlane (2002), A coupled climate model simulation of the Last Glacial Maximum, Part 1: transient multi-decadal response, Climate Dynamics, 19 , 515-537.

Klaas, C., and D. E. Archer (2002), Association of sinking organic matter with various types of mineral ballast in the deep sea: Implications for the rain ratio, Global Biogeochemical Cycles, 16, 1116, doi: 10.1029/2001GB001,765.

Knorr, G., and G. Lohmann (2003), Southern Ocean origin for the resumption of Atlantic thermohaline circulation during deglaciation, Nature, 424, 532-536.

Knox, F., and M. B.McElroy (1984), Changes in atmospheric $\mathrm{CO}_{2}$ : Influence of the marine biota at high latitude, Journal of Geophysical Research, 89(D3), 4629-4637.

Knutti, R., J. Flückiger, T. F. Stocker, and A. Timmermann (2004), Strong hemispheric coupling of glacial climate through continental freshwater discharge and ocean circulation, Nature, 430, 851856.

Koeve, W. (2002), Upper ocean carbon fluxes in the Atlantic Ocean: the importance of the POC:PIC ratio, Global Biogeochemical Cycles, 16, 1056, 10.1029/GB001,836.

Kohfeld, K. E., C. L. Quere, S. Harrison, and R. F. Anderson (2005), Role of marine biology in glacial-interglacial $\mathrm{CO}_{2}$ cycles, $\mathrm{Sci}$ ence, 308, 74-78.

Köhler, P., and H. Fischer (2004), Simulating changes in the terrestrial biosphere during the last glacial/interglacial transition, Global and Planetary Change, 43, 33-55, doi: 10.1016/j.gloplacha. 2004.02.005.

Köhler, P., F. Joos, S. Gerber, and R. Knutti (2005), Simulated changes in vegetation distribution, land carbon storage, and atmospheric $\mathrm{CO}_{2}$ in response to a collapse of the North Atlantic thermohaline circulation, Climate Dynamics, pp. in press, doi: 10.1007/s00,382-005-0058-8.

Körtzinger, A., J. I. Hedges, and P. D. Quay (2001), Redfi eld ratios revisited: Removing the biasing effect of anthropogenic $\mathrm{CO}_{2}$, Limnology and Oceanography, 46, 946-970.

Kroopnick, P. M. (1985), The distribution of ${ }^{13} \mathrm{C}$ of $\sum \mathrm{CO}_{2}$ in the world oceans, Deep-Sea Research A, 32, 57-84.

Kumar, N., R. F. Anderson, R. A. Mortlock, P. N. Froelich, P. Kubik, B. Dittrich-Hannen, and M. Suter (1995), Increased biological productivity and export production in the glacial Southern Ocean, Nature, 378, 675-680.

Kutzbach, J., R. Gallimore, S. Harrison, P. Behling, R. Selin, and F. Laarif (1998), Climate and biome simulations for the past 21,000 years, Quaternary Science Reviews, 17, 473-506.

Labeyrie, L. D., J. C. Duplessy, and P. L. Blanc (1987), Variations in mode of formation and temperature of oceanic deep waters over the past 125,000 years, Nature, $327,477-482$. 
Laj, C., C. Kissel, A. Mazaud, E. Michel, R. Muscheler, and J. Beer (2002), Geomagnetic fi eld intensity, North Atlantic Deep Water circulation and atmospheric $\Delta^{14} \mathrm{C}$ during the last $50 \mathrm{kyr}$, Earth and Planetary Science Letters, 200, 177-190.

Lea, D. W., D. K. Pak, and H. J. Spero (2000), Climate impact of late Quaternary equatorial Pacific sea surface temperature variations, Science, 289, 1719-1724.

LeGrand, P., and K. Alverson (2001), Variations in atmospheric $\mathrm{CO}_{2}$ during glacial cycles from an inverse ocean modelling perspective, Paleoceanography, 16, 604-616.

Leuenberger, M. C., M. Eyer, P. Nyfeler, B. Stauffer, and T. F. Stocker (2003), High-resolution $\delta^{13} \mathrm{C}$ measurements on ancient air extracted from less than $10 \mathrm{~cm}^{3}$ of ice, Tellus, 55B, 138-144.

Levitus, S., and T. Boyer (1994a), World Ocean Atlas Volume 2: Oxygen, NOAA Atlas NESDIS 2, U.S. Department of Commerce, Washington, D.C.

Levitus, S., and T. Boyer (1994b), World Ocean Atlas Volume 4: Temperature, NOAA Atlas NESDIS 4, U.S. Department of Commerce, Washington, D.C.

Levitus, S., R. Burgett, and T. Boyer (1994), World Ocean Atlas Volume 3: Salinity, NOAA Atlas NESDIS 3, U.S. Department of Commerce, Washington, D.C.

Marchal, O., T. F. Stocker, and F. Joos (1998a), A latitude-depth, circulation-biogeochemical ocean model for paleoclimate studies. Development and sensitivities, Tellus, 50B, 290-316.

Marchal, O., T. F. Stocker, and F. Joos (1998b), Impact of oceanic reorganizations on the ocean carbon cycle and atmospheric carbon dioxide content, Paleoceanography, 13(3), 225-244.

Marchal, O., T. F. Stocker, F. Joos, A. Indermühle, T. Blunier, and J. Tschumi (1999), Modelling the concentration of atmospheric $\mathrm{CO}_{2}$ during the Younger Dryas climate event, Climate Dynamics, $15,341-354$.

Marchal, O., T. F. Stocker, and R. Muscheler (2001), Atmospheric radiocarbon during the Yonger Dryas: production, ventilation, or both?, Earth and Planetary Science Letters, 185, 383-395.

Martin, J. H. (1990), Glacial-interglacial $\mathrm{CO}_{2}$ change: the iron hypothesis, Paleoceanography, 5, 1-13.

Martin, P. A., D. W. Lea, Y. Rosenthal, N. J. Shackleton, M. Sarnthein, and T. Papenfuss (2002), Quaternary deep sea temperature histories derived from benthic foraminferal $\mathrm{Mg} / \mathrm{Ca}$, Earth and Planetary Science Letters, 198, 193-209.

Masarik, J., and J. Beer (1999), Simulation of particle fluxes of cosmogenic nuclide production in the Earth's atmosphere, Journal of Geophysical Research, 104(D10), 12,099-12,111.

Matsumoto, K., J. L. Sarmiento, and M. A. Brzezinski (2002), Silicic acid leakage from the Southern Ocean: a possible explanation for glacial atmospheric $p \mathrm{CO}_{2}$, Global Biogeochemical Cycles, 16, 10.1029/2001GB001,442.

McManus, J. F., D. W. Oppo, and J. L. Cullen (1999), A 0.5-millionyear record of millennial-scale climate variability in the North Atlantic, Science, 283, 971-975.

McManus, J. F., R. Francois, J.-M. Gheradi, L. D. Keigwin, and S. Brown-Leger (2004), Collapse and rapid resumption of Atlantic meridional circulation linked to deglacial climate changes, Nature, 428, 834-837.

McPhaden, M. J., and D. Zang (2002), Slowdown of the meridional overturning circulation in the upper Pacifi c Ocean, Nature, 415, 603-608.

Meese, D. A., A. Gow, R. Alley, G. Zielinski, P. Grootes, M. Ram, K. Taylor, P. Mayewski, and J. Bolzan (1997), The Greenland Ice Sheet Project 2 depth-age scale: Methods and results, Journal of Geophysical Research, 102, 26,411-26,423.

Meissner, K. J., A. Schmittner, A. J. Weaver, and J. F. Adkins (2003), Ventilation of the North Atlantic Ocean during the
Last Glacial Maximum: a comparison between simulated and observed radiocarbon ages, Paleoceanography, 18, 1023, doi: 10.1029/2002PA000,762.

Millero, F. J., K. Lee, and M. Roche (1998), Distribution of alkalinity in the surface waters of the major oceans, Marine Chemistry, 60, 111-130.

Milliman, J. D. (1993), Production and accumulation of calcium carbonate in the ocean: budget of a nonsteady state, Global Biogeochemical Cycles, 7, 927-957.

Mix, A. C., N. G. Pisias, R. Zahn, R. C. Lopez, and K. Nelson (1991), Carbon 13 in Pacifi c deep and inter mediate waters, 0370 ka: implications for ocean circulation and Pleistocene $\mathrm{CO}_{2}$, Paleoceanography, 6, 205-226.

Mix, A. C., J. Le, and N. J. Shackleton (1995), Benthic foraminiferal stable isotope stratigraphy of Site 846: 0-1.8 Ma, in Proceedings of the Ocean Drilling Program, Scientific Results Vol 138, edited by N. G. Pisias, L. Mayer, T. Janecek, A. PalmerJulson, and T. van Andel, pp. 839-854, College Station, Texas, USA.

Monnin, E., A. Indermühle, A. Dällenbach, J. Flückiger, B. Stauffer, T. F. Stocker, D. Raynaud, and J.-M. Barnola (2001), Atmospheric $\mathrm{CO}_{2}$ concentrations over the last glacial termination, Science, 291, 112-114.

Mook, W. G. (1986), ${ }^{13} \mathrm{C}$ in atmospheric $\mathrm{CO}_{2}$, Netherlands Journal of Sea Research, 20(2/3), 211-223.

Moore, J. K., M. R. Abbott, J. G. Richman, and D. M. Nelson (2000), The Southern Ocean at the Last Glacial Maximum: a strong sink for atmospheric carbon dioxide, Global Biogeochemical Cycles, 14, 455-475.

Morales-Maqueda, M. A., and S. Rahmstorf (2001), Did Antarctic sea-ice expansion cause glacial $\mathrm{CO}_{2}$ decline?, Geophysical Research Letters, 29, 10.1029/2001GRL013,240.

Mulitza, S., H. Arz, S. K. von Mücke, C. Moss, H.-S. Niebler, J. Pätzold, and M. Segl (1999), The South Atlantic Carbon Isotope record of planktic foraminifera, in Use of proxies in $\mathrm{Pa}$ leoceanography: Examples from the South Atlantic, edited by G. Fischer and G. Wefer, pp. 427-445, Springer Verlag, Berlin, Heidelberg, Germany.

Munhoven, G. (1997), Modelling glacial-interglacial atmospheric $\mathrm{CO}_{2}$ variations: the role of continental weathering, Ph.D. thesis, Université de Liège, Liège, Belgium.

Munhoven, G. (2002), Glacial-interglacial changes of continental weathering: estimates of the related $\mathrm{CO}_{2}$ and $\mathrm{HCO}_{3}^{-}$flux variations and their uncertainties, Global and Planetary Change, 33, $155-176$.

Munhoven, G., and L. M. François (1996), Glacial-interglacial variability of atmospheric $\mathrm{CO}_{2}$ due to changing continental silicate rock weathering: a model study, Journal of Geophysical Research, 101(D16), 21,423-21,437.

Muscheler, R., J. Beer, G. Wagner, C. Laj, C. Kissel, G. M. Raisbeck, F. Yiou, and P. W. Kubik (2004), Changes in the carbon cycle during the last deglaciation as indicated by the comparison of ${ }^{10} \mathrm{Be}$ and ${ }^{14} \mathrm{C}$ records, Earth and Planetary Science Letters, 219, 325-340.

Nürnberg, D., A. Müller, and R. R. Schneider (2000), Paleo-sea surface temperature calculations in the equatorial east Atlantic from $\mathrm{Mg} / \mathrm{Ca}$ ratios in planktic foraminifera: A comparison to sea surface temperature estimates from $\mathrm{U}_{37}^{K^{\prime}}$, oxygen isotopes, and foraminiferal transfer function, Paleoceanography, 15, 124-134.

Opdyke, B. N., and J. C. G. Walker (1992), Return of the coral reef hypothesis: basin to shelf partioning of $\mathrm{CaCO}_{3}$ and its effect on atmospheric $\mathrm{CO}_{2}$, Geology, 20, 733-736.

Oppo, D. W., and S. J. Lehman (1993), Mid-depth circulation of the subpolar North Atlantic during the Last Glacial Maximum, 
Science, 259, 1148-1152.

Paillard, D., and F. Parrenin (2004), The Antarctic ice sheet and the triggering of deglaciations, Earth and Planetary Science Letters, 227, 263-271.

Passow, U. (2004), Switching perspectives: Do mineral fluxes determine particulate organic carbon fluxes or vice versa?, Geochemistry, Geophysics, Geosystems, 5, Q04,002, doi: 10.1029/2003GC000,670.

Peterson, L. C., and W. L. Prell (1985), Carbonate preservation and rates of climate change: an $800 \mathrm{kyr}$ record from the Indian Ocean, in The carbon cycle and atmospheric $\mathrm{CO}_{2}$ : Natural variations archean and present, Geophysical Monograph, vol. 32, edited by E. T. Sundquist and W. S. Broecker, pp. 251269, American Geophysical Union, Washington, D.C., USA.

Pfhumann, U., M. Sarnthein, M. Chapman, L. d'Abreu, B. Funnell, M. Huels, T. Kiefer, M. Maslin, H. Schulz, J. Swallow, S. van Kreveld, M. Vautravers, E. Vogelsang, and M. Weinelt (2003), Glacial North Atlantic: Sea-surface conditions reconstructed by GLAMAP2000, Paleoceanography, 18, 1065, doi: 10.1029/2002PA000,774.

Prieto, F. J. M., and F. J. Millero (2002), The values of $\mathrm{pK}_{1}+\mathrm{pK}_{2}$ for the dissolution of carbonic acid in seawater, Geochimica et Cosmochimica Acta, 66, 2529-2540.

Qiu, B., and R. Huang (1995), Ventilation of the North Atlantic and North Pacifi c: subduction versus obduction, Journal of Physical Oceanography, 25, 2374-2390.

Rahmstorf, S. (2002), Ocean circulation and climate during the paste 120,000 years, Nature, 419, 207-214.

Rau, G. H., U. Riebesell, and D. Wolf-Gladrow (1996), A model of photosynthetic ${ }^{13} \mathrm{C}$ fractionation by marine phytoplankton based on diffusive molecular $\mathrm{CO}_{2}$ uptake, Marin Ecology Progress Series, 133, 275-285.

Rau, G. H., U. Riebesell, and D. Wolf-Gladrow (1997), $\mathrm{CO}_{2 \mathrm{aq}^{-}}$ dependent photosynthetic ${ }^{13} \mathrm{C}$ fractionation in the ocean: a model versus measurements, Global Biogeochemical Cycles, 11, 267-278.

Ridgwell, A. J. (2001), Glacial-interglacial pertubations in the global carbon cycle, Ph.D. thesis, University of East Anglia, Norwich, U.K.

Ridgwell, A. J. (2003a), An end to the rain ratio reign?, Geochemistry, Geophysics, Geosystems, 4, 1051, doi: $10.1029 / 2003 \mathrm{GC} 000,512$.

Ridgwell, A. J. (2003b), Implications of the glacial $\mathrm{CO}_{2}$ iron hypothesis for Quaternary climate change, Geochemistry, Geophysics, Geosystems, 4, 1076, doi: 10.1029/2003GC000,563.

Ridgwell, A. J., and A. J. Watson (2002), Feedback between aeolian dust, climate, and atmospheric $\mathrm{CO}_{2}$ in glacial time, Paleoceanography, 17, 1059, 10.1029/2001PA000,729.

Robinson, R. S., B. G. Brunelle, and D. M. Sigman (2004), Revisiting nutrient utilization in the glacial Antarctic: Evidence from a new method for diatom-bound $\mathrm{N}$ isotopic analysis, Paleoceanography, 19, PA3001, doi: 10.1029/2003PA000,996.

Röthlisberger, R., R. Mulvaney, E. W. Wolff, M. A. Hutterli, M. Bigler, S. Sommer, and J. Jouzel (2002), Dust and sea salt variability in central East Antarctica (Dome C) over the last 45 kyrs and its implications for southern high-latitude climate, Geophysical Research Letters, 29, 1963, 10.1029/GL015,186.

Röthlisberger, R., M. Bigler, E. W. Wolff, E. Monnin, F. Joos, and M. Hutterli (2004), Ice core evidence for the extent of past atmospheric $\mathrm{CO}_{2}$ change due to iron fertilization, Geophysical Research Letters, 31, L16,207, doi: 10.1029/2004GL020,338.

Saltzman, J., and K. F. Wishner (1997), Zooplankton ecology in the eastern tropical Pacifi c oxygen minimum zone above a seamount: 1. General trend, DSRI, 44, 907-930.
Sarmiento, J. L., and J. R. Toggweiler (1984), A new model for the role of the oceans in determining atmospheric $P_{\mathrm{CO}_{2}}$, Nature, 308, 621-624.

Sarmiento, J. L., J. C. Orr, and U. Siegenthaler (1992), A pertubation simulation of $\mathrm{CO}_{2}$ uptake in an ocean general circulation model, Journal of Geophysical Research, 97(C3), 3621-3645.

Sarmiento, J. L., J. Dunne, A. Gnanadesikan, R. M. Key, K. Matsumoto, and R. Slater (2002), A new estimate of the $\mathrm{CaCO}_{3}$ to organic carbon export ratio, Global Biogeochemical Cycles, 16, 1107, doi: 10,1029/2002GB001,919.

Sarnthein, M., U. Pfhumann, and M. Weinelt (2003), Past extent of sea ice in the northern North Atlantic inferred from foraminiferal paleotemperature estimates, Paleoceanography, 18, 1047, doi: 10.1029/2002PA000,771.

Schiebel, R. (2002), Planktic foraminiferal sedimentation and the marine calcite budget, Global Biogeochemical Cycles, 16, 1065, 10.1029/2001GB001,459.

Schlitzer, R. (2000), Applying the adjoint method for biogeochemical modelling: export of particulate organic matter in the world ocean, in Inverse methods in Global Biogeochemical Cycles, Geophysical Monographs, vol. 114, edited by P. Kasibhatla, M. Heimann, P. Rayner, N. Mahowald, R. G. Prinn, and D. E. Hartley, pp. 107-124, AGU, Washington, D.C.

Schlitzer, R. (2002), Carbon export fluxes in the Southern Ocean: results from inverse modeling and comparison with satellitebased estimates, Deep-Sea Research II, 49, 1623-1644.

Scholze, M., W. Knorr, and M. Heimann (2003), Modelling terrestrial vegetation dynamics and carbon cycling for an abrupt climate change event, The Holocene, 13, 327-333.

Schulz, M., D. Seidov, M. Sarnthein, and K. Stattegger (2001), Modelling ocean-atmosphere carbon budgets during the Last Glacial Maximum-Heinrich 1 meltwater event-Bølling transition, International Journal of Earth Sciences, 90, 412-425.

Siegenthaler, U., and T. Wenk (1984), Rapid atmospheric $\mathrm{CO}_{2}$ variations and ocean circulation, Nature, 308, 624-626.

Sigman, D. M., and E. A. Boyle (2000), Glacial/interglacial variations in atmospheric carbon dioxide, Nature, 407, 859-869.

Sigman, D. M., D. C. McCorkle, and W. R. Martin (1998), The calcite lysocline as a constraint on glacial/interglacial low-latitude production changes, Global Biogeochemical Cycles, 12(3), 409427.

Slowey, N. C., and W. B. Curry (1995), Glacial-interglacial differences in circulation and carbon cycling within the upper western North Atlantic, Paleoceanography, 10, 715-732.

Sloyan, B. M., and S. R. Rintoul (2001), The Southern Ocean limb of the global deep overturning circulation, Journal of Physical Oceanography, 31, 143-173.

Smith, H. J., H. Fischer, M. Wahlen, D. Mastroianni, and B. Deck (1999), Dual modes of the carbon cycle since the Last Glacial Maximum, Nature, 400, 248-250.

Spero, H. J., and D. W. Lea (2002), The cause of carbon isotope minimum events on glacial terminations, Science, 296, 522-525.

Spero, H. J., J. Bijma, D. W. Lea, and B. E. Bemis (1997), Effect of seawater carbonate concentration on foraminiferal carbon and oxygen isotopes, Nature, 390, 497-500.

Stenni, B., V. Masson-Delmotte, S. Johnsen, J. Jouzel, A. Longinelli, E. Monnin, R. Röthlisberger, and E. Selmo (2001), An oceanic cold reversal during the last deglaciation, Science, 293, 2074-2077.

Stephens, B. B., and R. F. Keeling (2000), The influence of Antarctic sea ice on glacial-interglacial $\mathrm{CO}_{2}$ variations, Nature, 404, 171-174.

Stocker, T. F., and D. G. Wright (1996), Rapid changes in ocean circulation and atmospheric radiocarbon, Paleoceanography, 11, 
773-795.

Stuiver, M., H. G. Östlund, and T. A. McConnaughey (1981), GEOSECS Atlantic and Pacifi $\mathrm{c}^{14} \mathrm{C}$ distribution, in Carbon cycle modelling, SCOPE, vol. 16, edited by B. Bolin, pp. 201-221, Wiley and Sons, Chichester, New York, Brisbane, Toronto.

Stuiver, M., P. J. Reimer, E. Bard, J. W. B. andd G. S. Burr, K. A. Hughen, B. Kromer, G. McCormac, J. van der Plicht, and M. Spurk (1998), INTCAL98 radiocarbon age calibration, 24,000-0 cal BP, Radiocarbon, 40, 1041-1083.

Takahashi, T., W. S. Broecker, and A. E. Bainbridge (1981), The alkalinity and total carbon dioxide concentration in the world oceans, in Carbon cycle modelling, SCOPE, vol. 16, edited by B. Bolin, pp. 271-286, Wiley and Sons, Chichester, New York, Brisbane, Toronto.

Takahashi, T., S. C. Sutherland, C. Sweeney, A. Poisson, N. Metzl, B. Tilbrook, N. Bates, R. Wanninkhof, R. A. F. andd C. Sabine, J. Olafsson, and Y. Nojiri (2002), Global sea-air $\mathrm{CO}_{2}$ flux based on climatological surface ocean $p \mathrm{CO}_{2}$, and seasonal biological and temperature effects, Deep-Sea Research II, 49, 1601-1622.

Toggweiler, J. R. (1999), Variation of atmospheric $\mathrm{CO}_{2}$ by ventilation of the ocean's deepest water, Paleoceanography, 14(5), 571-588.

Toggweiler, J. R., and J. L. Sarmiento (1985), Glacial to interglacial changes in atmospheric carbon dioxide: the critical role of ocean surface water in high latitudes, in The carbon cycle and atmospheric $\mathrm{CO}_{2}$ : Natural variatins Archean to present, Geophysical Monographs, vol. 32, edited by E. T. Sundquist and W. S. Broecker, pp. 163-184, AGU, Washington, D.C.

Toggweiler, J. R., A. Gnanadesikan, S. Carson, R. Murnane, and J. L. Sarmiento (2003a), Representation of the carbon cycle in box models and GCMs: 1. Solubility pump, Global Biogeochemical Cycles, 17, 1026, doi: 10.1029/2001GB001,401.

Toggweiler, J. R., R. Murnane, S. Carson, A. Gnanadesikan, and J. L. Sarmiento (2003b), Representation of the carbon cycle in box models and GCMs: 2. Organic pump, Global Biogeochemical Cycles, 17, 1027, doi: 10.1029/2001GB001,841.

Vecsei, A. (2004), Carbonate production on isolated banks since 20 k.a. BP: climatic implications, Palaeogeography, Palaeoclimatology, Palaeoecology, 214, 3-10.

Vecsei, A., and W. H. Berger (2004), Increase of atmospheric $\mathrm{CO}_{2}$ during deglaciation: constraints on the coral reef hypothesis from patterns of deposition, Global Biogeochemical Cycles, 18, GB 1035, doi: 10.1029/2003GB002,147.

Vinnikov, K. Y., A. Robock, R. J. Stouffer, J. E. Walsh, C. L. Parkinson, D. J. Cavalieri, J. F. B. Mitchell, D. Garrett, and V. F. Zakharov (1999), Global warming and northern hemisphere sea ice extent, Science, 286, 1934-1937.

Visser, K., R. Thunell, and L. Stott (2003), Magnitude and timing of temperature change in the Indo-Pacifi c warm pool during deglaciation, Nature, 421, 152-155.

Wanninkhof, R. (1992), Relationship between wind speed and gas exchange over the ocean, Journal of Geophysical Research, 97(C5), 7373-7382.

Watson, A. J., D. C. E. Bakker, A. J. Ridgwell, P. W. Boyd, and C. S. Law (2000), Effect of iron supply on Southern Ocean $\mathrm{CO}_{2}$ uptake and implications for glacial atmospheric $\mathrm{CO}_{2}$, Nature, 407, 730-733.

Winguth, A. M. E., D. Archer, J.-C. Duplessy, E. Maier-Reimer, and U. Mikolajewicz (1999), Sensitivity of paleonutrient tracer distributions and deep-sea circulation to glacial boundary conditions, Paleoceanography, 14, 304-323.

Wunsch, C. (1984), An estimate of the upwelling rate in the equatorial Atlantic based on the distribution of bomb radiocarbon and quasigeostrophic dynamics, Journal of Geophysical Research,
89, 7971-7978.

Zeebe, R. E. (2005), Simple ocean carbon cycle models: New insights into evaluating glacial $\mathrm{CO}_{2}$ scenarios and predictions of anthropogenic $\mathrm{CO}_{2}$ uptake by the ocean, Global Biogeochemical Cycles, p. submitted.

Zeebe, R. E., and P. Westbroek (2003), A simple model for the $\mathrm{CaCO}_{3}$ saturation state of the ocean: the Strangelove, the Neritan, and the Cretan Ocean, Geochemistry, Geophysics, Geosystems, 4, 1104, doi: 10.1029/2003GC000,538.

Zeebe, R. E., and D. A. Wolf-Gladrow (2001), $\mathrm{CO}_{2}$ in Seawater: Equilibrium, Kinetics, Isotopes, Elsevier Oceanography Book Series, vol. 65, 346 pp., Elsevier Science Publishing, Amsterdam, The Netherlands.

Zhang, J., P. D. Quay, and D. O. Wilbur (1995), Carbon isotope fractionation during gas-water exchange and dissolution of $\mathrm{CO}_{2}$, Geochimica et Cosmochimica Acta, 59, 107-114. 


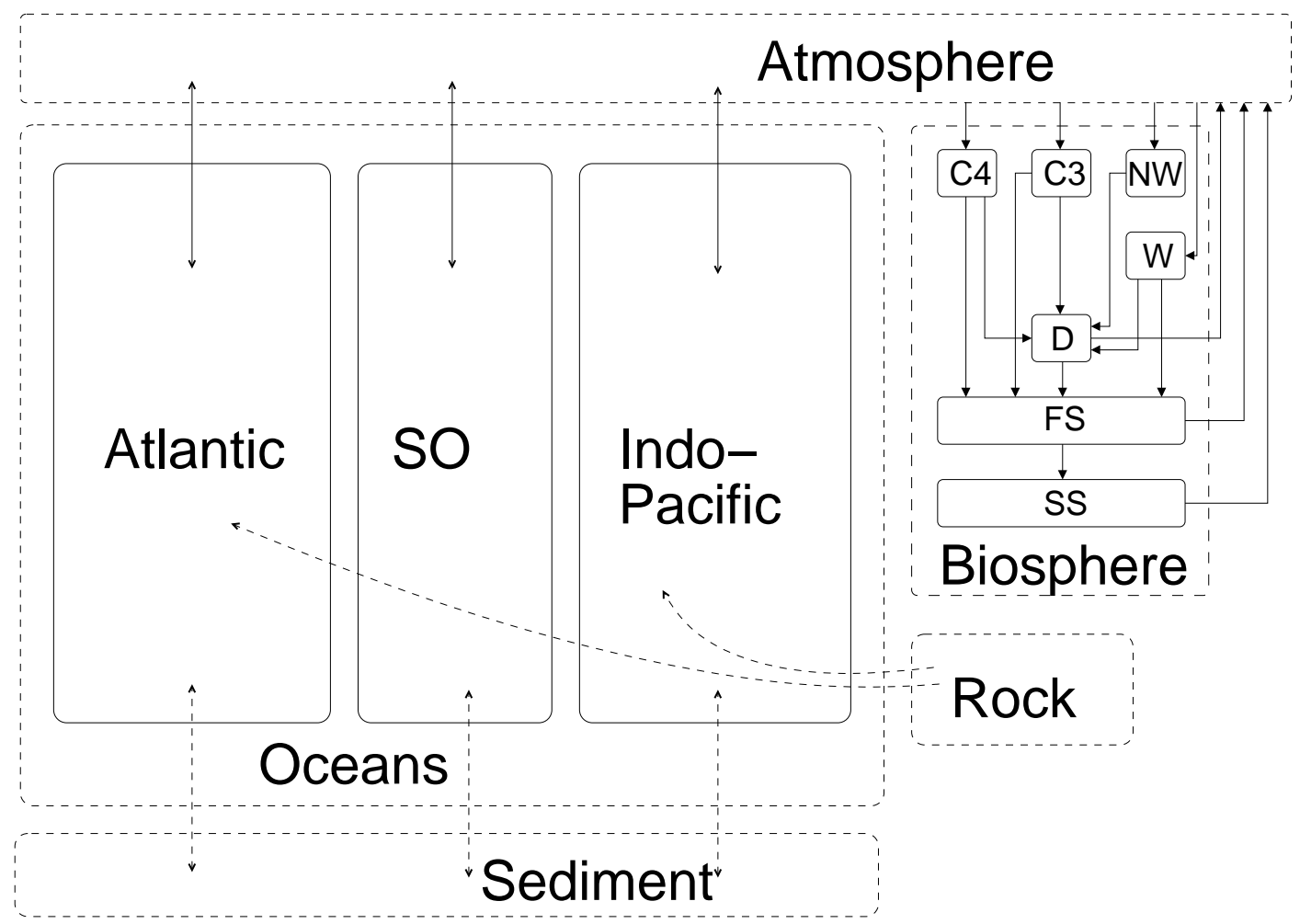

Fig. 1. Geometry of the Box model of the Isotopic Carbon cYCLE (BICYCLE). Carbon fluxes between different reservoirs are shown. Biosphere compartments: $\mathrm{C} 4: \mathrm{C}_{4}$ ground vegetation; $\mathrm{C} 3: \mathrm{C}_{3}$ ground vegetation; $\mathrm{NW}$ : non-woody parts of trees; W: woody parts of trees; $\mathrm{D}$ : detritus; FS: fast decomposing soil; SS: slow decomposing soil.

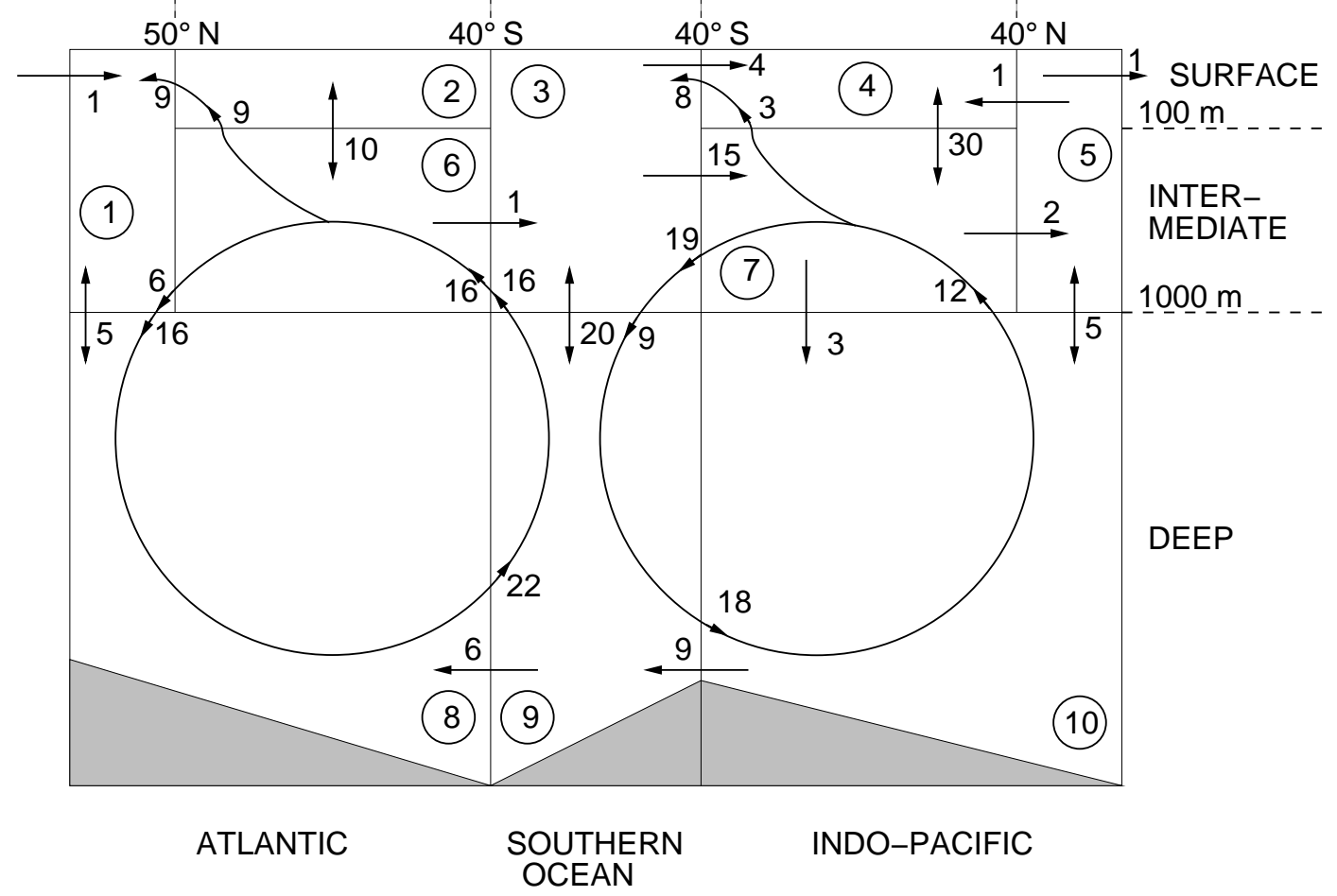

Fig. 2. Geometry of the ocean box model and recent fluxes of ocean circulation (in $\mathrm{Sv}=10^{6} \mathrm{~m}^{3} \mathrm{~s}^{-1}$ ). Box numbers are given in circles. 

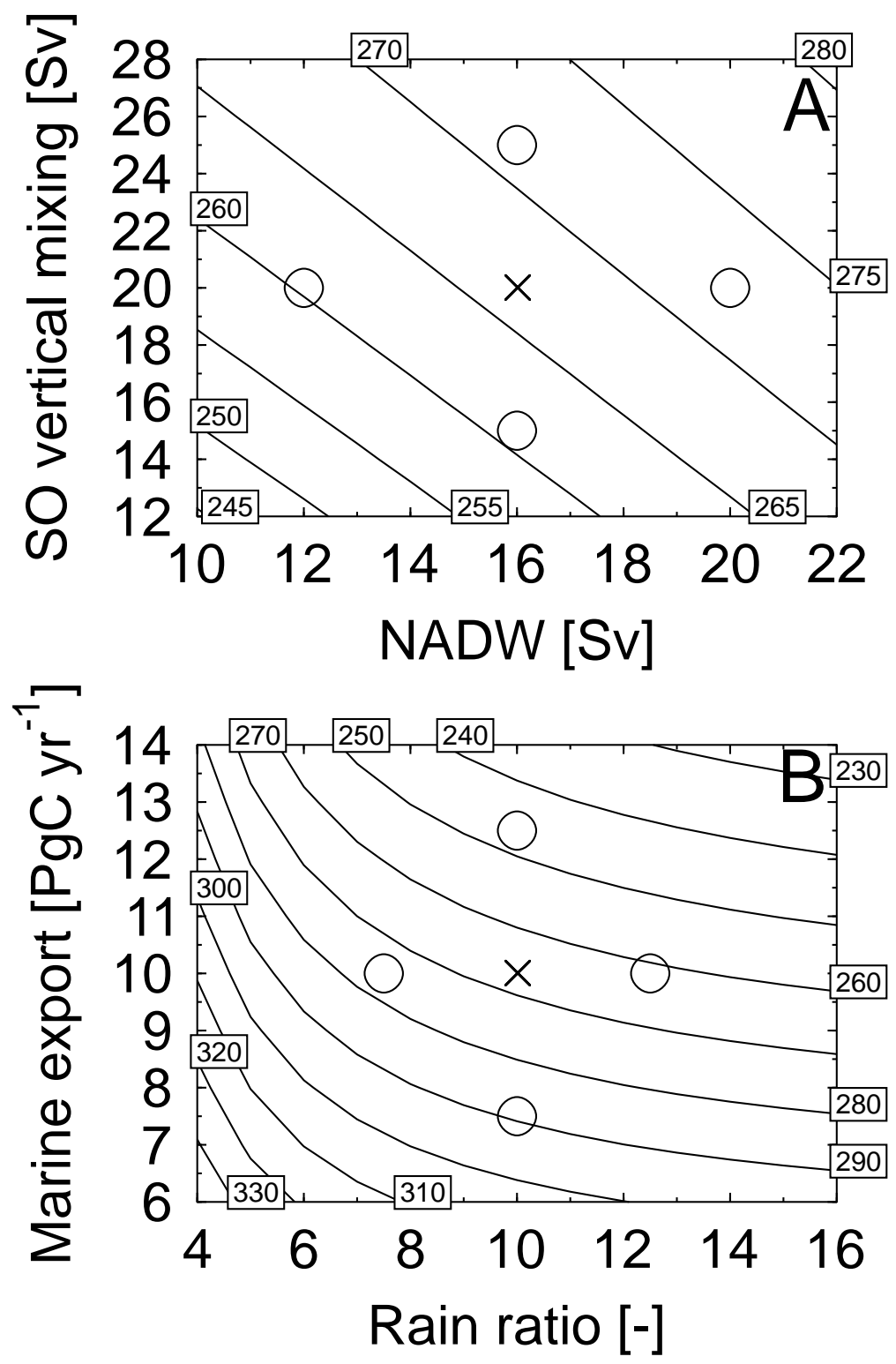

Fig. 3. Contours of atmospheric $p \mathrm{CO}_{2}$ and its sensitivity to various parameters. A: Variations in the ocean circulation (strength of NADW formation and Southern Ocean vertical mixing rate). B: Variations in the biological pump (global marine export production and rain ratio of organic carbon to $\mathrm{CaCO}_{3}$ ). Crosses mark the $p \mathrm{CO}_{2}$ of our preindustrial reference run, circles mark variations of $25 \%$ in one parameter. 


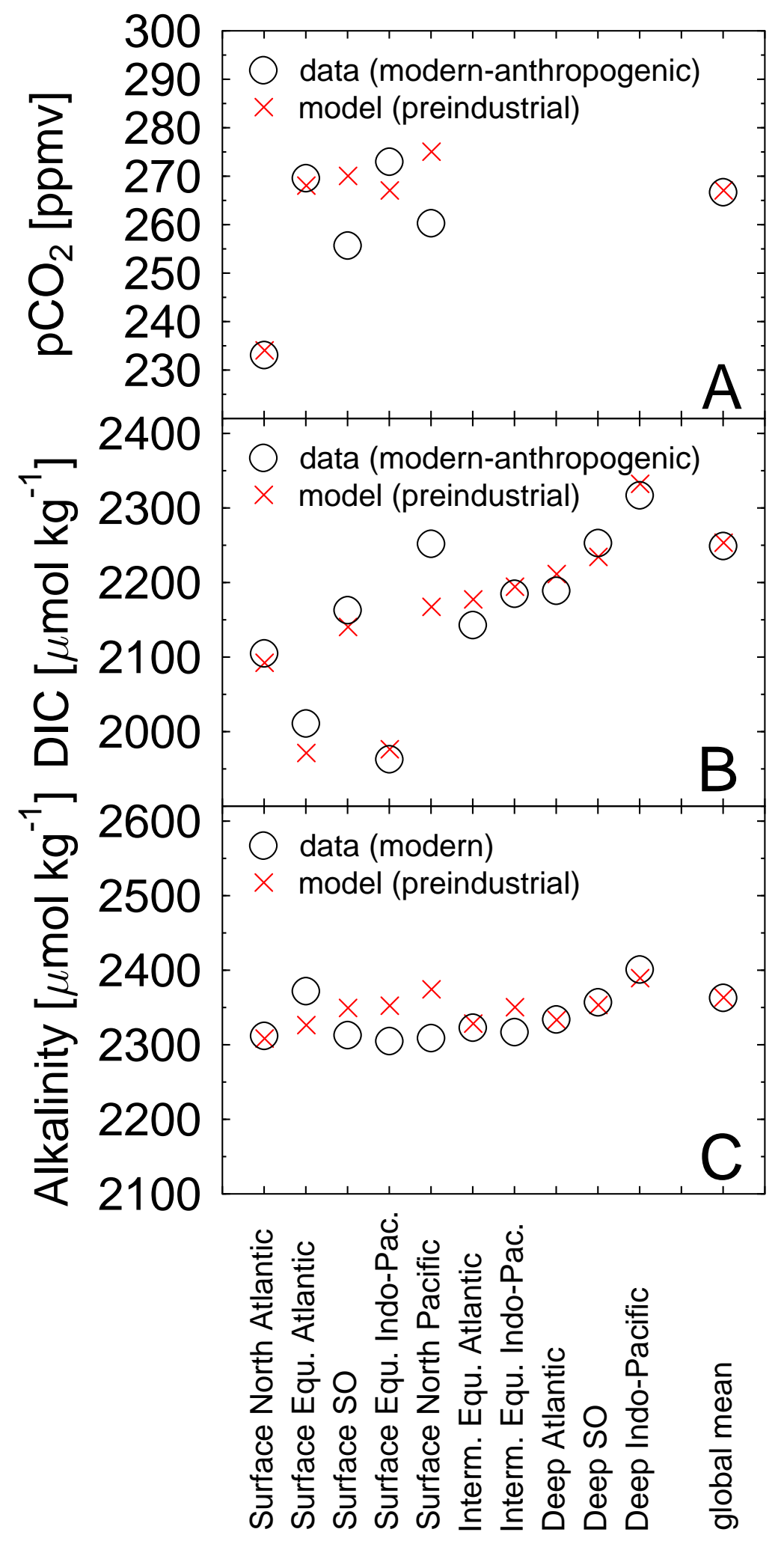

Fig. 4. Comparison of (A) $p \mathrm{CO}_{2}$, (B) DIC, and (C) alkalinity from the preindustrial reference run with data. $\mathrm{Modern} p \mathrm{CO}_{2}$ data from Takahashi et al. [2002] corrected by $82 \mathrm{ppmv}$ (anthropogenic component) in order to yield the same global mean $p \mathrm{CO}_{2}$ as in the model. DIC and alkalinity from GLODAP [Key et al., 2004]. DIC data were corrected for anthropogenic carbon. 


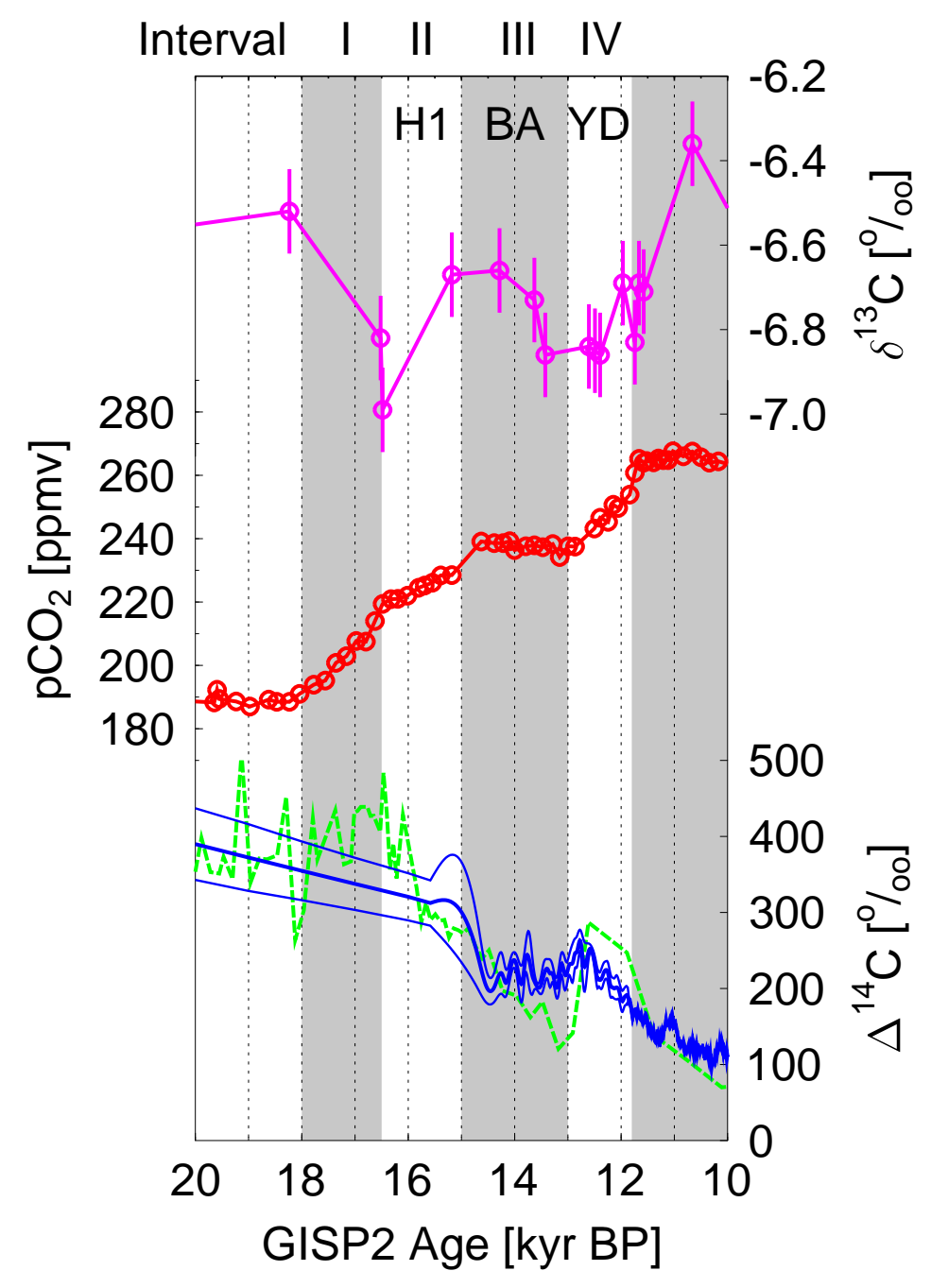

Fig. 5. Measured atmospheric carbon records. Atmospheric $\delta^{13} \mathrm{C}$ in the Taylor Dome ice core [Smith et al., 1999]; $p \mathrm{CO}_{2}$ in the EPICA Dome $\mathrm{C}$ ice core divided in four intervals with different changing rates [Monnin et al., 2001]; $\Delta^{14} \mathrm{C}$ from INTCAL98 (blue line with error range in thin lines) [Stuiver et al., 1998] and new data from the Cariaco Basin (green line) [Hughen et al., 2004]. The intervals II, III, and IV are approximately identical with the Heinrich 1 event (H1), the Bølling-Allerød warm interval (BA), and the Younger Dryas cold event (YD) in the North Atlantic region. 


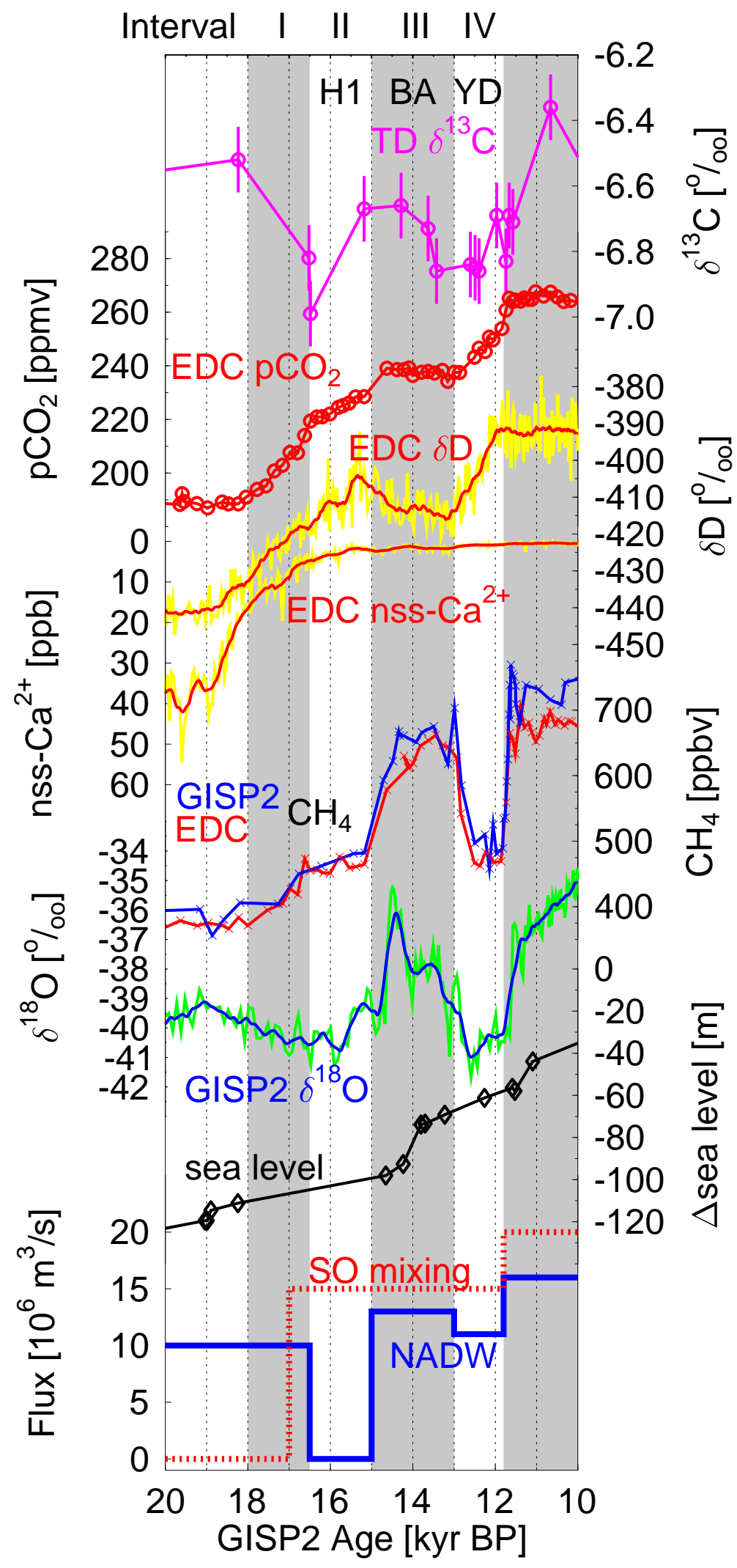

Fig. 6. Time dependent forcing functions of the model during termination I. Atmospheric $\delta^{13} \mathrm{C}$ in the Taylor Dome ice core [Smith et al., 1999]; $p \mathrm{CO}_{2}$ in the EPICA Dome C (EDC) ice core divided in four intervals with different changing rates [Monnin et al., 2001]; $\delta \mathrm{D}$ from EDC as isotopic temperature proxies for southern high latitude [Jouzel et al., 2001]; nss-Ca ${ }^{2+}$ record in EDC as proxy for Southern Ocean dust/Fe input [Röthlisberger et al., 2002]; $\mathrm{CH}_{4}$ from EDC and GISP2 ice cores [Brook et al., 1996; Monnin et al., 2001] used for synchronizing EDC records to the GISP2 age scale [Meese et al., 1997]; $\delta^{18} \mathrm{O}$ from the GISP2 ice core as isotopic temperature proxy for northern high latitude [Grootes and Stuiver, 1997]; sea level changes derived from coral reef terraces (on an individual time scale) [Fairbanks, 1990]. Strongly fluctuating records $\left(\delta^{18} \mathrm{O}, \delta \mathrm{D}, \mathrm{nss}-\mathrm{Ca}^{2+}\right)$ are low-pass fil ltered using a $500 \mathrm{yr}$ running mean. $\delta^{13} \mathrm{C}$ was synchronized via $p \mathrm{CO}_{2}$ to the atmospheric carbon record of EDC. Shown are also the assumed changes in the amplitude of NADW formation and the strength of vertical mixing in the Southern Ocean over time. 


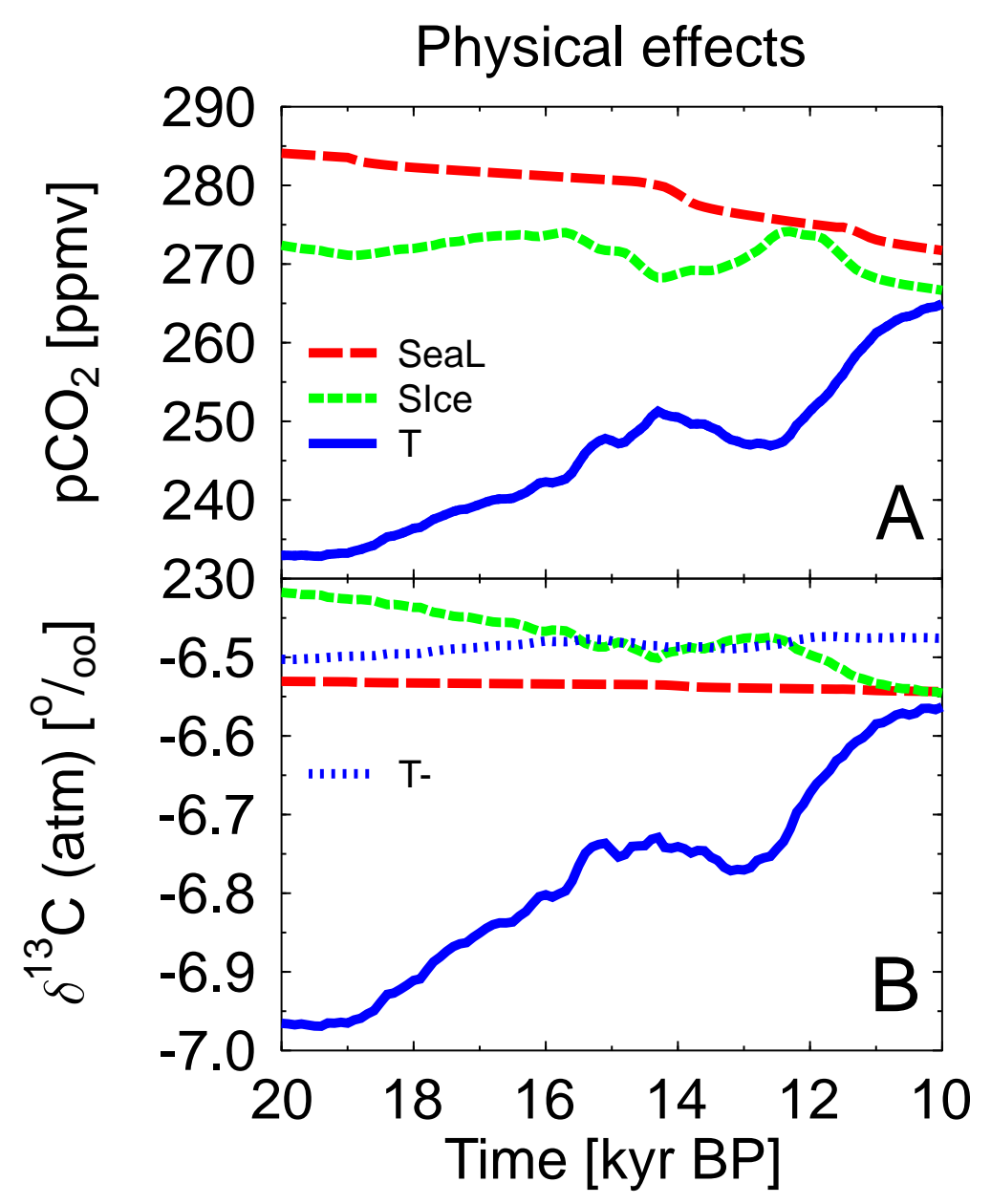

Fig. 7. Simulation of physical impacts of sea level rise (SeaL), sea ice extensions (SIce), and temperature effects (T) on atmospheric carbon records $\left(\mathrm{A}: p \mathrm{CO}_{2}, \mathrm{~B}: \delta^{13} \mathrm{C}\right)$. The temperature-dependent solubility affects both $p \mathrm{CO}_{2}$ and $\delta^{13} \mathrm{C}$, while the temperature-dependent isotopic fractionation during gas exchange only affects $\delta^{13} \mathrm{C}$ (T-: solubility only, T: combined effects). 


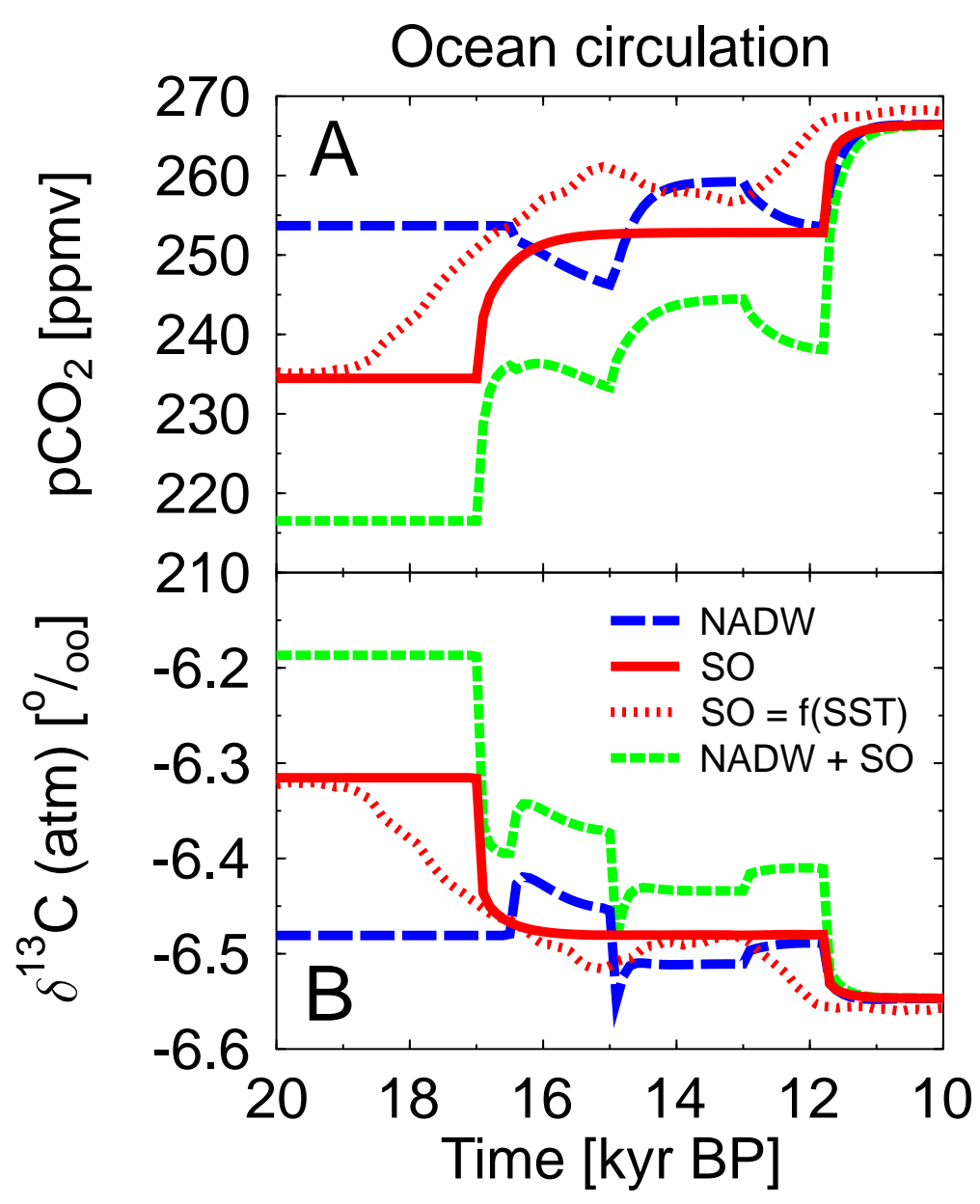

Fig. 8. Simulated impacts of time-dependent variations in the strength of NADW formation and Southern Ocean (SO) vertical mixing on atmospheric carbon records (A: $p \mathrm{CO}_{2}, \mathrm{~B}: \delta^{13} \mathrm{C}$ ). We vary the strength of NADW formation (NADW), or Southern Ocean mixing (SO), or both simultaneously (NADW $+\mathrm{SO}$ ) as plotted in Fig. 6. Alternatively, Southern Ocean mixing is varied as a function of SST (SO $=\mathrm{f}(\mathrm{SST})$ ). 


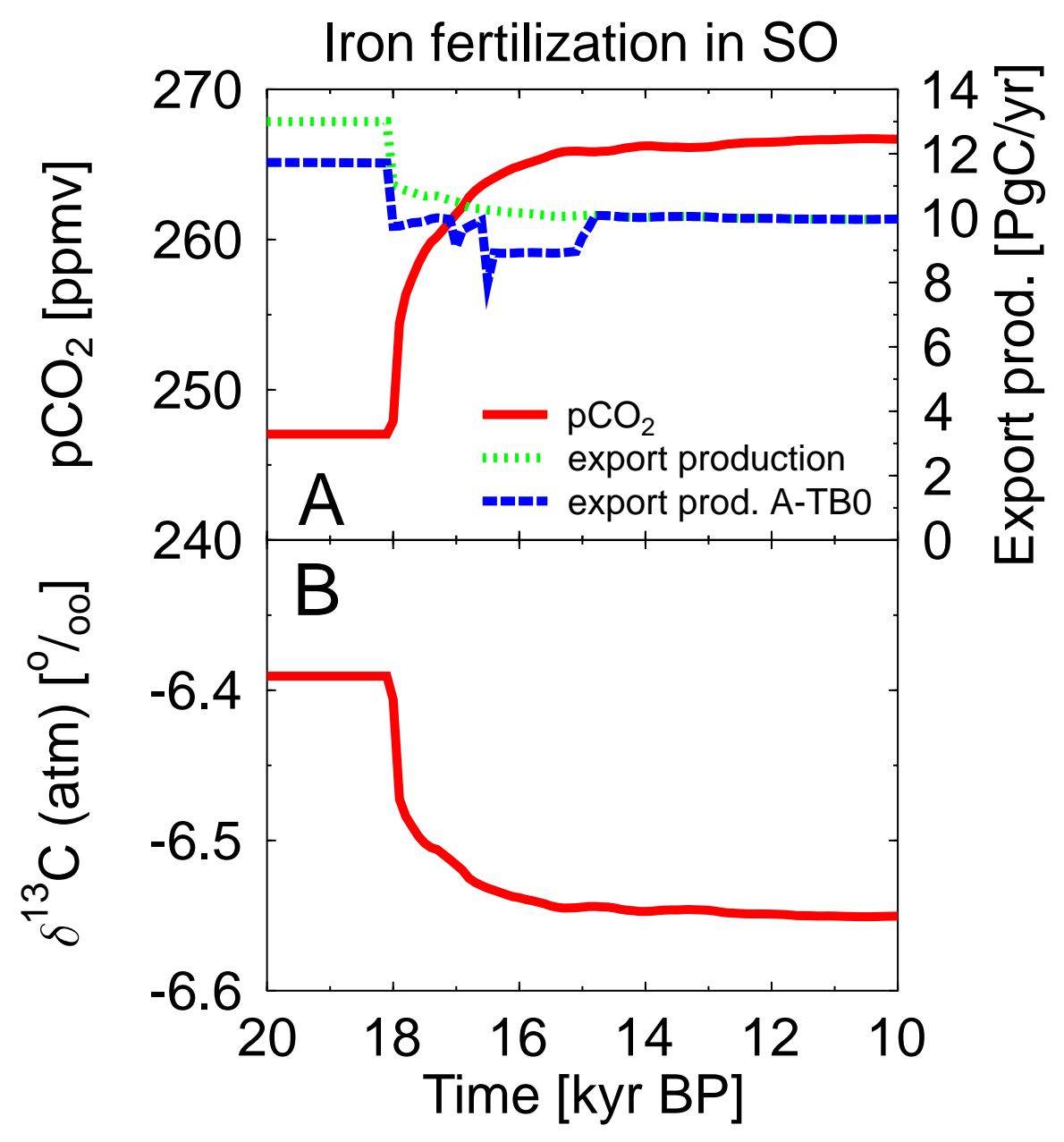

Fig. 9. Simulated effects of iron fertilization in the Southern Ocean on atmospheric carbon records $\left(\mathrm{A}: p \mathrm{CO}_{2}, \mathrm{~B}: \delta^{13} \mathrm{C}\right)$. The single process impact of $\mathrm{Fe}$ fertilization compared with its impact in the scenario A-TB0 combining all forcings on the marine export production at $100 \mathrm{~m}$ water depth is shown additionally. High fluctuations in the export production in A-TB0 are due to macro nutrient depletion. 


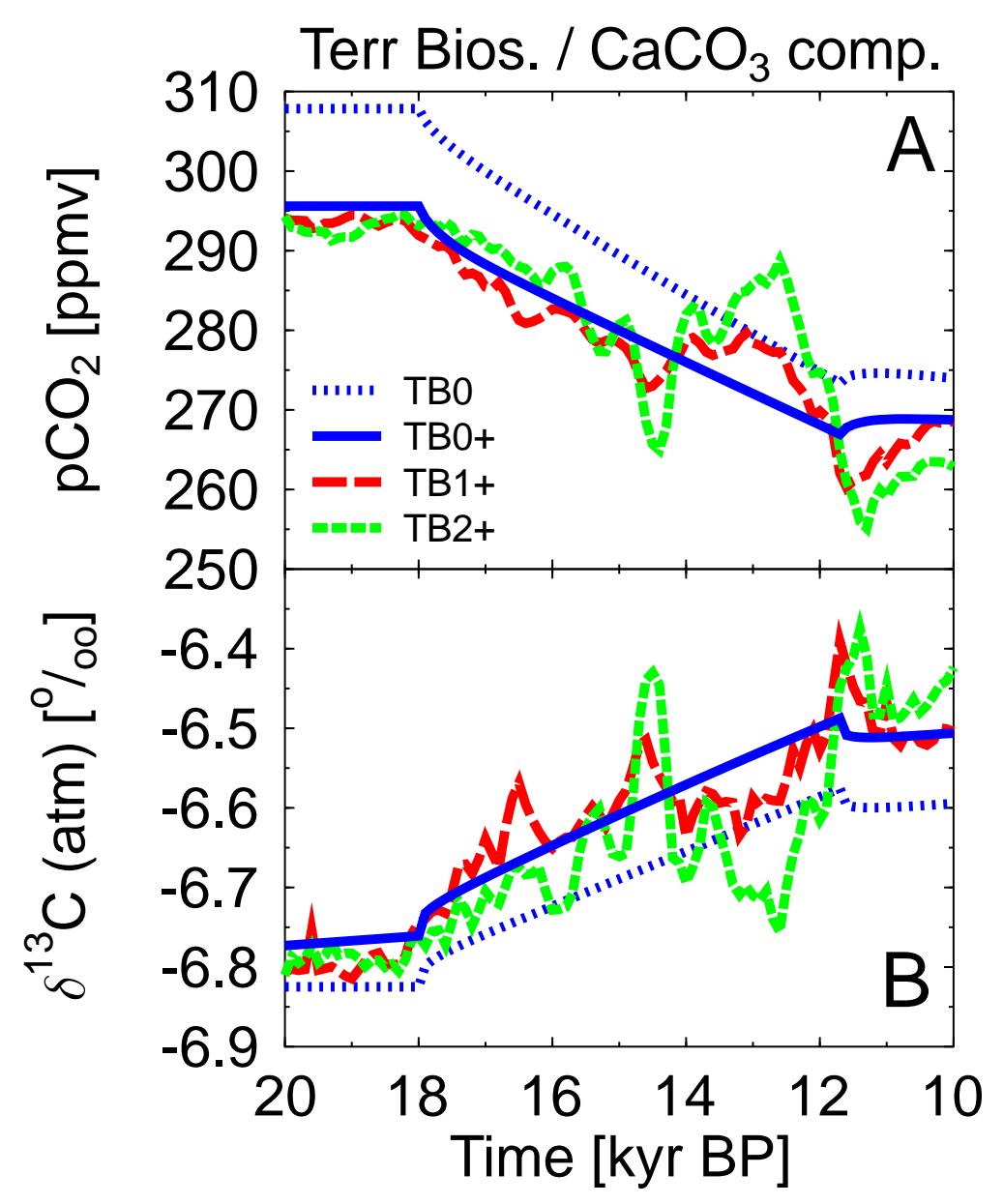

Fig. 10. Simulated impacts of changes in the terrestrial biosphere on atmospheric carbon records $\left(\mathrm{A}: p \mathrm{CO}_{2}, \mathrm{~B}: \delta^{13} \mathrm{C}\right)$. Additionally, carbonate compensation is realized by boundary conditions on the G/IG changes in the lysoclines which lead to fluxes of DIC and alkalinity in the ratio 1:2 between sediment and deep ocean. The biosphere follows in a null-model a linear increase (TB0+) or two different dependencies dominated by $\mathrm{CO}_{2}$ fertilization (TB1+) or climate (TB2+) as plotted in Fig. 11A. Sole impact of the growth of the terrestrial biosphere without carbonate compensation is plotted as example for the null model (TB0). 


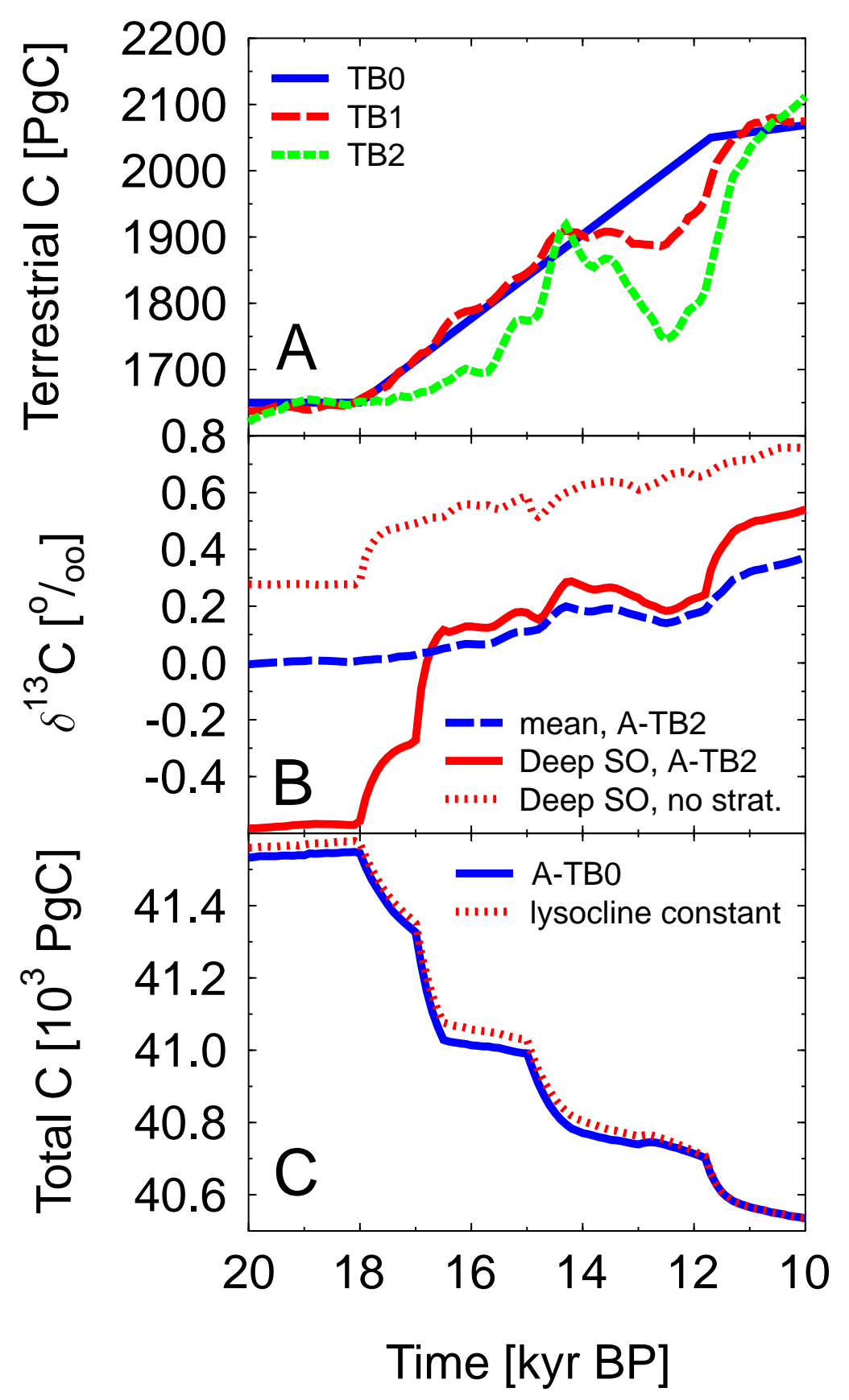

Fig. 11. Additional simulation results. A: Changes in the terrestrial biosphere, scenarios as described in Fig. 10. B: Overall mean change in oceanic $\delta^{13} \mathrm{C}$ and in the Southern Ocean $\delta^{13} \mathrm{C}$ with (A-TB2) and without changes in Southern Ocean stratifi cation. C: Total carbon budget of the ocean-atmosphere-biosphere system for scenarios with a constant lysocline or with prescribed changes of the lysocline over time (A-TB0). 


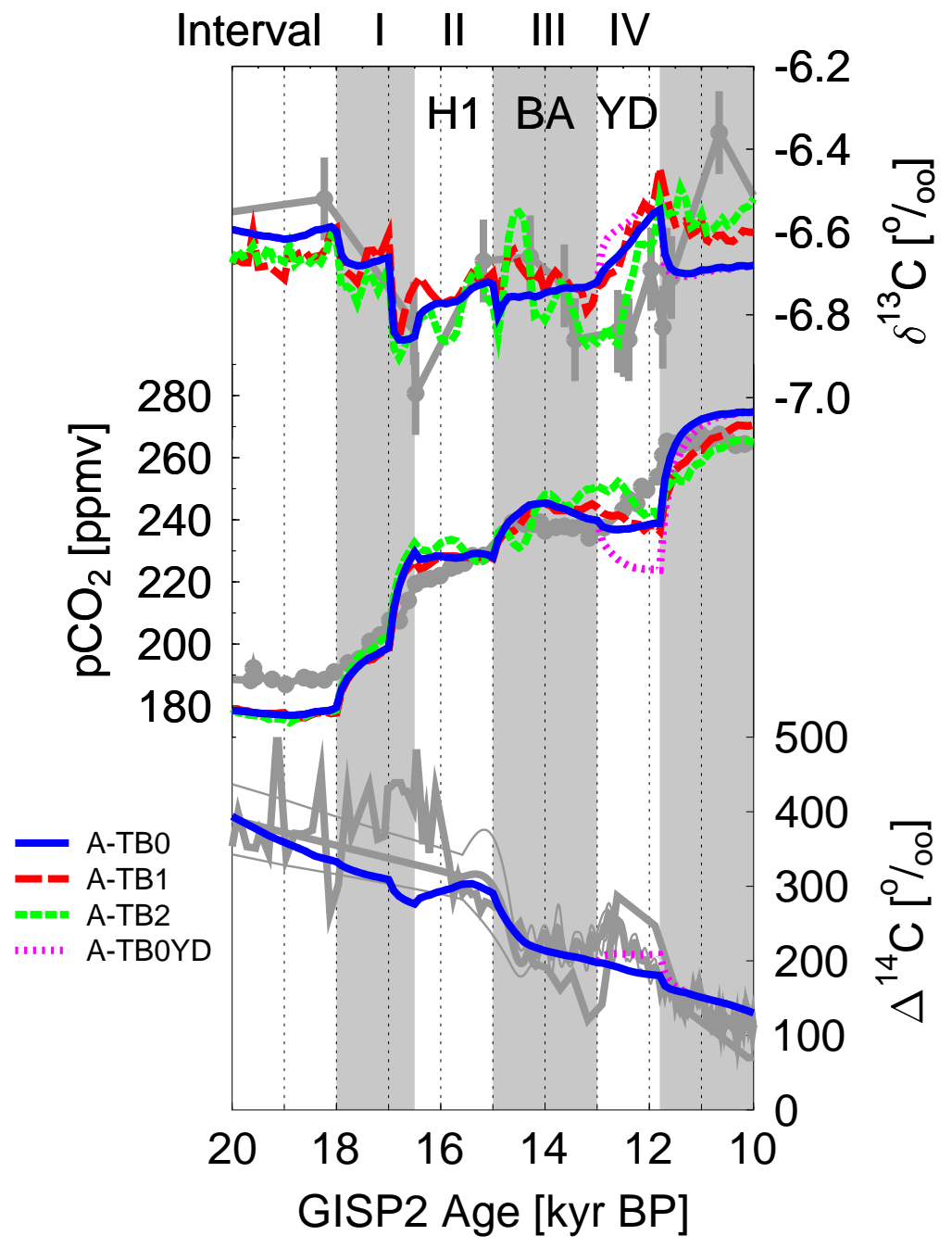

Fig. 12. Measured and simulated atmospheric carbon records. Data records (grey) as in Fig. 5. Simulation scenarios combine all physical processes (ocean temperature, sea level, sea ice) with changes in ocean circulation (NADW formation, Southern Ocean mixing), marine export production, $\mathrm{CaCO}_{3}$ compensation and terrestrial biosphere as described in Fig. 10. A-TB0YD: Same as A-TB0 but with NADW formation shut-off during the Younger Dryas. 


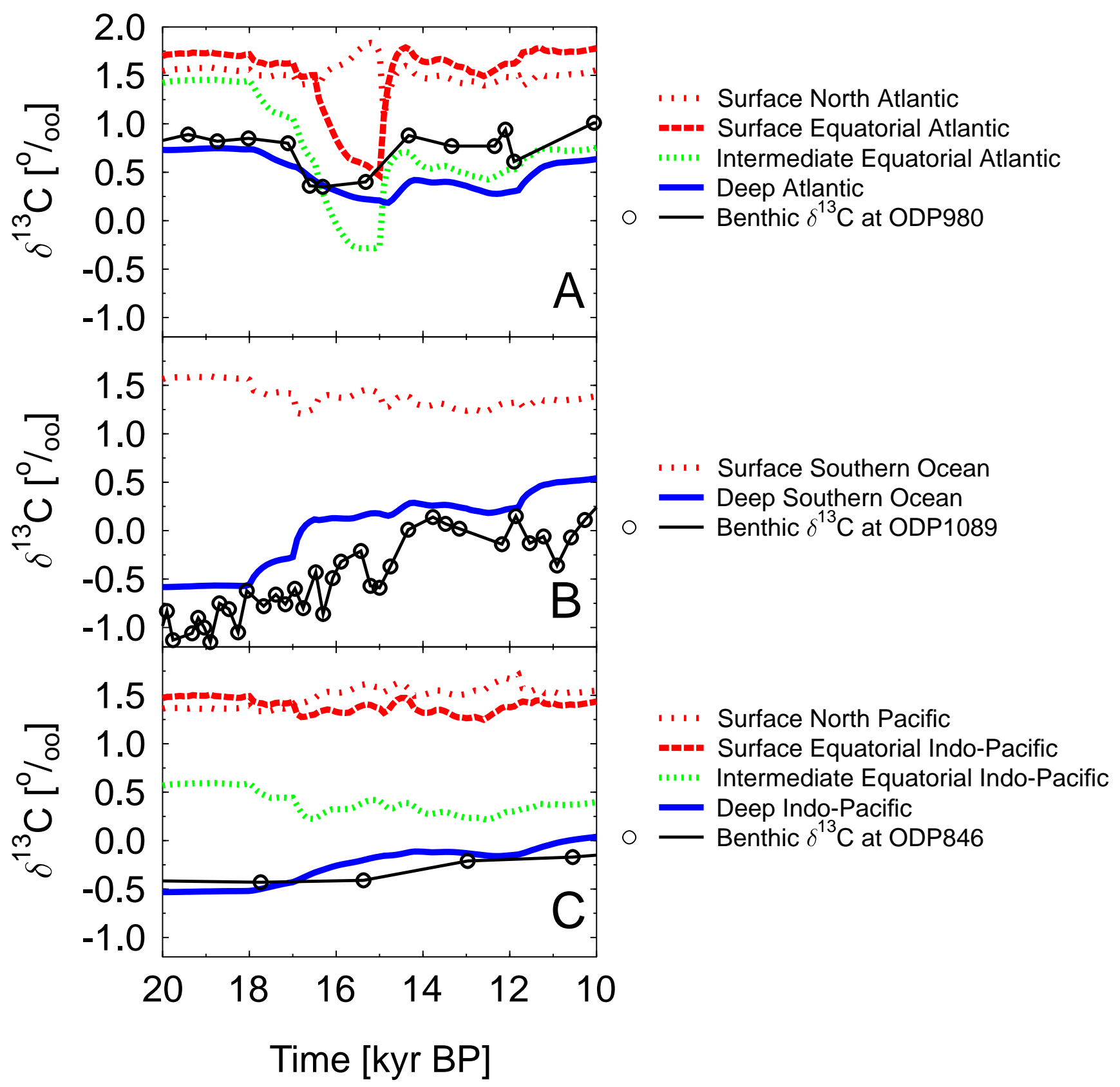

Fig. 13. Temporal evolution of oceanic $\delta^{13} \mathrm{C}$ in all ocean boxes over Termination I in comparison to selected data records of $\delta^{13} \mathrm{C}$ in benthic

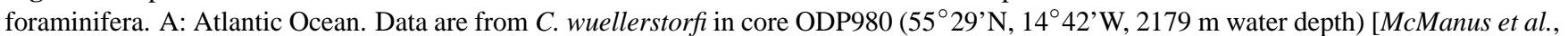
1999]. B: Southern Ocean. Data are from Cibicidoides spp. in core ODP1089 (40 $56^{\prime}$ S, $9^{\circ} 54^{\prime}$ E, 4621 m water depth) [Hodell, 2002; Hodell et al., 2003]. C: Indo-Pacifi c Ocean. Data are from C. wuellerstorfi and U. peregrina in core ODP846 (35' S, $90^{\circ} 82^{\prime} \mathrm{W}, 3296 \mathrm{~m}$ water depth) [Mix et al., 1995]. 
Table 1. Ocean settings for the preindustrial reference run. Weathering flux and ocean/sediment exchange off. $\mathrm{C} \exp =10 \mathrm{PgC} \mathrm{yr}^{-1}$, $\mathrm{C}_{\mathrm{exp}}: \mathrm{CaCO}_{3}=10$, both at $100 \mathrm{~m}$ water depth.

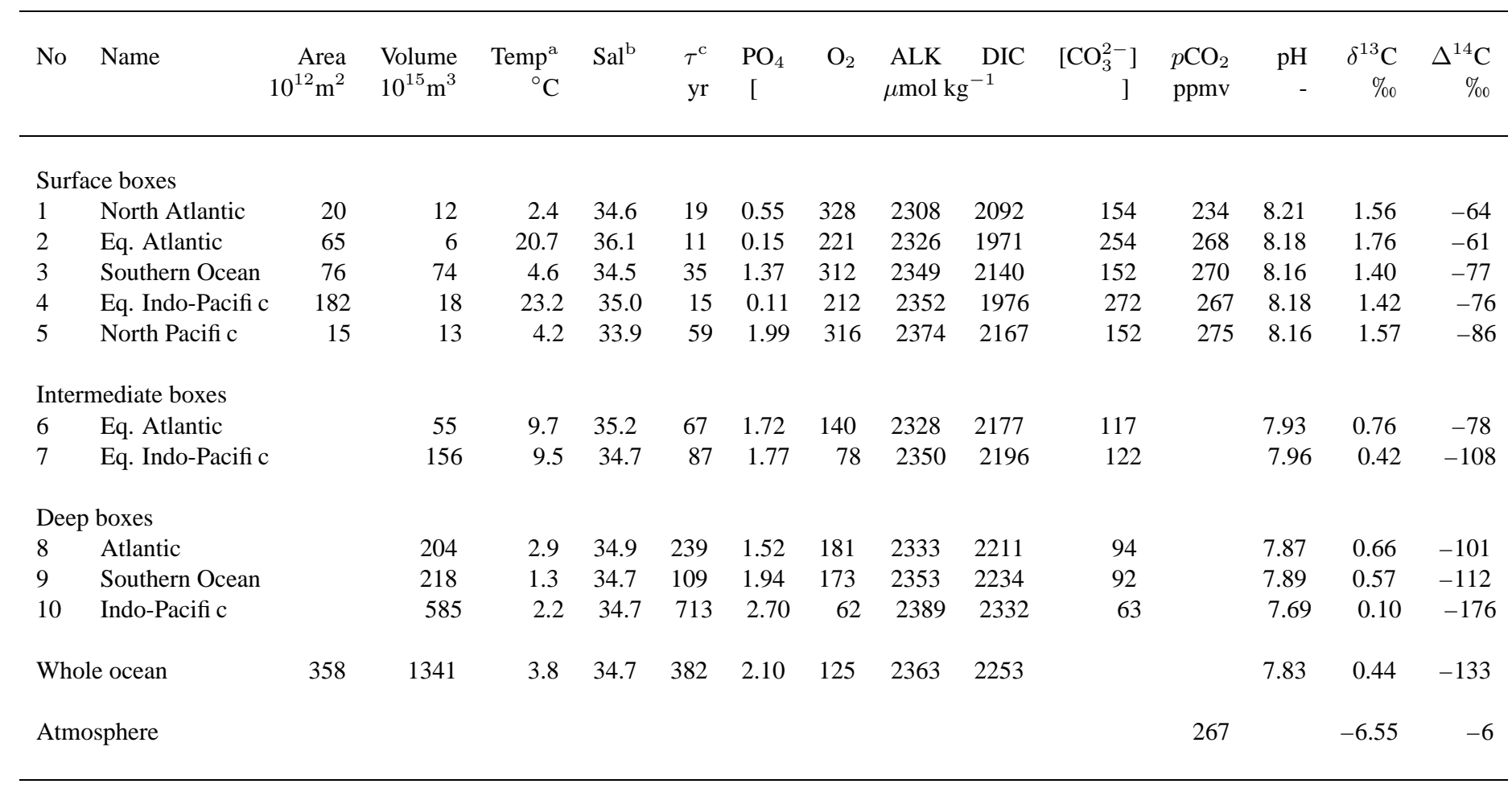

${ }^{\text {a }}$ Prescribed from WOA [Levitus and Boyer, 1994b].

${ }^{\mathrm{b}}$ Prescribed from WOA [Levitus et al., 1994].

${ }^{\mathrm{c}}$ Turnover time. 
Table 2. Contribution of different processes on the observed changes in atmospheric $p \mathrm{CO}_{2}$ during Termination I (11.5 - $\left.18 \mathrm{kyr} \mathrm{BP}\right)$. As the processes influence each other both their individual impact and the effect during combined scenarios are summarized. A comparison of the impacts of all processes in combined scenarios is only useful for closed system simulations following mass conservation. But the sediment/ocean exchange processes change the inventories of ALK and DIC. We therefore analyze the impact of single processes in combined scenarios by their exclusion from scenario A-TB0 without sediment/ocean exchange processes. The simulation of changes in DIC and ALK inventories sums up the difference between the scenarios A-TB0 with and without sediment/ocean exchange. Summed up changes differ from simulated changes because of nonlinearities of the simulated carbon cycle system.

$\begin{array}{cc}\text { Process } & \begin{array}{c}\text { Modeled changes in } p \mathrm{CO}_{2}(\mathrm{ppmv}) \\ \text { individual process }\end{array} \\ \text { combined scenarios }\end{array}$

$\begin{array}{lrr}\text { Regrowth of terrestrial biosphere } & -34 & -6 \\ \text { Rise of sea level } & -12 & -2 \\ \text { Reduction of sea ice cover } & -5 & +1 \\ \text { Coral reef growth } & +3 & +16 \\ \text { Increase of the strenght of NADW formation } & +12 & +17 \\ \text { Rise of ocean temperatures } & +32 & +22 \\ \text { Reduction of marine export production } & +19 & +34 \\ \text { Variations in sedimentation/dissolution and weathering rates } & +7^{\mathrm{a}} & +37 \\ \text { Breakdown of Southern Ocean stratifi cation } & +37 & \\ & & +97 \\ \text { Summed up change } & & +87 \\ \text { Simulated changes in scenario A-TB0 } & +59 & -10 \\ \text { Nonlinearities } & & \end{array}$

a: Accompanied by the growth of the terrestrial biosphere.

Table 3. Ocean settings for the $20 \mathrm{kyr}$ BP in scenario A-TB0.

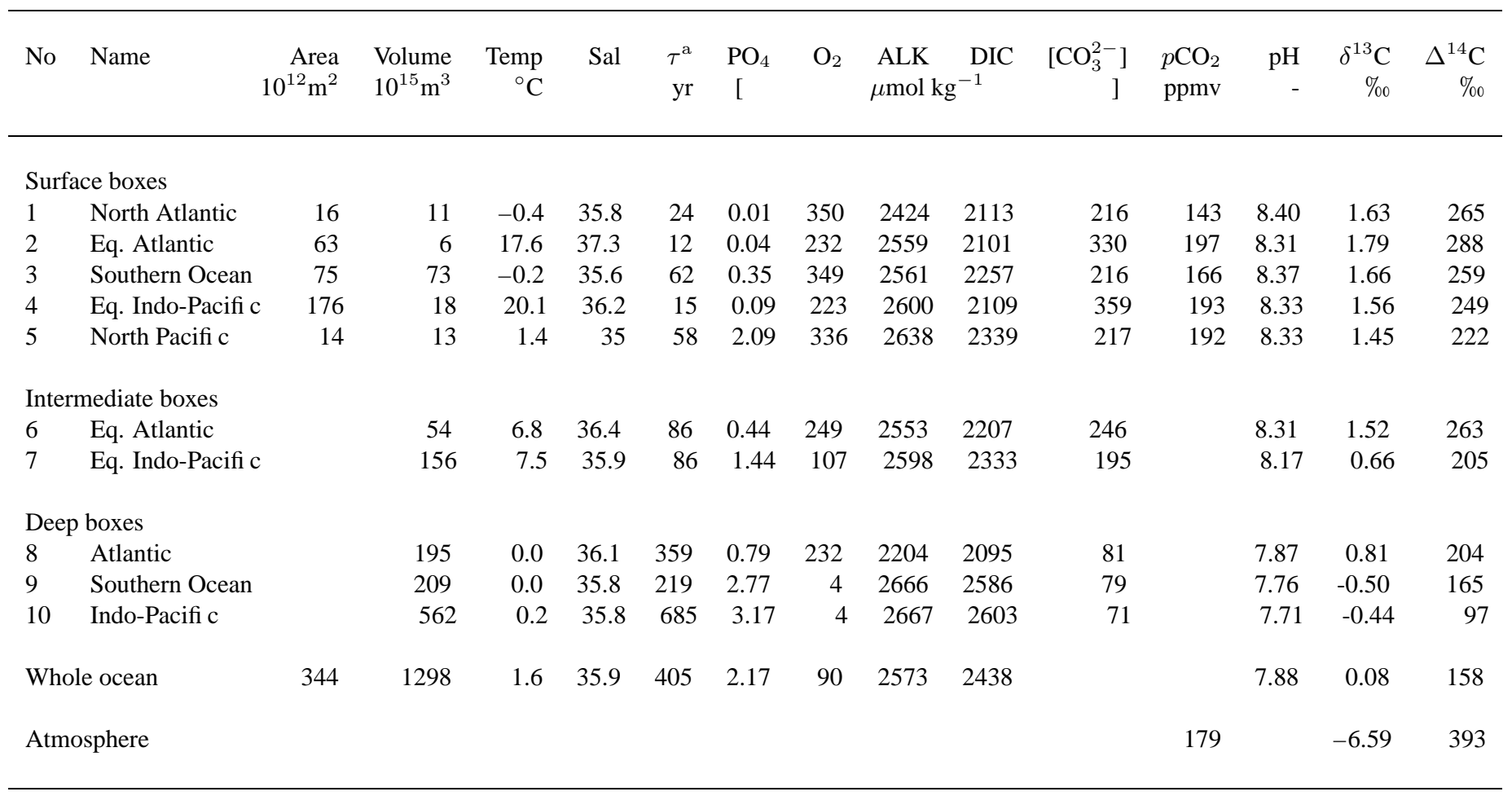

a: Turnover time. 